\title{
Repeated Amphetamine Exposure Disrupts Dopaminergic Modulation of Amygdala-Prefrontal Circuitry and Cognitive/Emotional Functioning
}

\author{
Maric T. L. Tse, Anna Cantor, and Stan B. Floresco \\ Department of Psychology and Brain Research Center, University of British Columbia, Vancouver, British Columbia, Canada, V6T 1Z4
}

\begin{abstract}
Repeated exposure to psychostimulants such as amphetamine (AMPH) disrupts cognitive and behavioral processes mediated by the medial prefrontal cortical (mPFC) and basolateral amygdala (BLA). The present study investigated the effects of repeated AMPH exposure on the neuromodulatory actions of dopamine (DA) on BLA-mPFC circuitry and cognitive/emotional processing mediated by these circuits. Rats received five AMPH (2 mg/kg) or saline injections (controls) over $10 \mathrm{~d}$, followed by 2-4 week drug washout. In vivo neurophysiological extracellular recordings in urethane-anesthetized rats were used to obtain data from mPFC neurons that were either inhibited or excited by BLA stimulation. In controls, acute AMPH attenuated BLA-evoked inhibitory or excitatory responses; these effects were mimicked by selective $\mathrm{D}_{2}$ or $\mathrm{D}_{1}$ agonists, respectively. However, in AMPH-treated rats, the ability of these dopaminergic manipulations to modulate BLA-driven decreases/increases in MPFC activity was abolished. Repeated AMPH also blunted the excitatory effects of ventral tegmental area stimulation on MPFC neural firing. Behavioral studies assessed the effect of repeated AMPH on decision making with conditioned punishment, a process mediated by BLA-mPFC circuitry and mesocortical DA. These treatments impaired the ability of rats to use conditioned aversive stimuli (footshock-associated cue) to guide the direction of instrumental responding. Collectively, these data suggest that repeated AMPH exposure can lead to persistent disruption of dopaminergic modulation of BLA-mPFC circuitry, which may underlie impairments in cognitive/emotional processing observed in stimulant abusers. Furthermore, they suggest that impairments in decision making guided by aversive stimuli observed in stimulant abusers may be the result of repeated drug exposure.
\end{abstract}

\section{Introduction}

Repeated exposure to psychostimulants, such as amphetamine (AMPH) or cocaine, has been associated with disruptions in cognitive and emotional processes mediated by amygdala-prefrontal cortical pathways in both humans and animals. These include increased impulsivity, cognitive inflexibility, and impaired decision making (Bechara et al., 2001; Monterosso et al., 2001; Ersche and Sahakian, 2007; Simon et al., 2007; Floresco and Whelan, 2009). Similarly, neuroimaging has revealed abnormal activation of the prefrontal cortex (PFC) and the amygdala of abusers (London et al., 2004; Ersche et al., 2005). The basolateral amygdala (BLA) appears to be particularly important for facilitating emotional regulation and decision making functions mediated by the medial PFC (mPFC). The BLA sends monosynaptic excitatory glutamate projections to the mPFC that synapse on both pyramidal and GABAergic interneurons (Gabbott et al., 2006), enabling

\footnotetext{
Received April 11, 2011; revised May 24, 2011; accepted June 16, 2011.

Author contributions: M.T.L.T. and S.B.F. designed research; M.T.L.T. and A.C. performed research; M.T.L.T. and S.B.F. analyzed data; M.T.L.T., A.C., and S.B.F. wrote the paper.

This work was supported by Canadian Institutes of Health Research Grant MOP 102478 (S.B.F.). S.B.F. is a Michael Smith Foundation for Health Research Senior Scholar.

Correspondence should be addressed to Dr. Stan B. Floresco, Department of Psychology and Brain Research Center, University of British Columbia, 2136 West Mall, Vancouver, BC, Canada, V6T 1Z4. E-mail: floresco@ psych.ubc.ca.

DOI:10.1523/JNEUROSCI.1810-11.2011

Copyright $\odot 2011$ the authors $\quad 0270-6474 / 11 / 3111282-13 \$ 15.00 / 0$
}

both excitation and feedforward inhibition of mPFC principle neurons.

Animal models have revealed that repeated exposure to AMPH or cocaine can perturb dopaminergic modulation of mPFC neural activity, which may contribute to cognitive dysfunction associated with these treatments. For example, repeated psychostimulant exposure reduces the number of dopamine (DA) terminals (Kadota and Kadota, 2004) and expression of DA receptors and related proteins in the PFC (Bowers et al., 2004; Briand et al., 2008). Likewise, these treatments attenuate DAmediated inhibition of neural activity in vivo and $\mathrm{D}_{1}$ receptor modulation of $\mathrm{Na}^{+} / \mathrm{K}^{+}$currents in PFC neurons in vitro (Peterson et al., 2000, 2006; Dong et al., 2005; Nogueira et al., 2006). Moreover, $\mathrm{D}_{1}$ receptor-mediated attenuation of excitatory responses in PFC slices evoked by stimulation of putative BLA afferents is disrupted in rats previously exposed to cocaine (Orozco-Cabal et al., 2008).

BLA stimulation reveals two distinct populations of mPFC projection neurons in vivo. Approximately $20 \%$ display monosynaptic excitatory responses, whereas the majority exhibit feedforward inhibition of spontaneous activity, likely mediated through activation of local GABAergic interneurons (PérezJaranay and Vives, 1991; Gabbott et al., 2006; Floresco and Tse, 2007). DA exerts neuromodulatory control over excitatory and inhibitory transmission in the BLA-PFC pathway via dissociable mechanisms. $\mathrm{D}_{1}$ but not $\mathrm{D}_{2 / 4}$ receptor activation suppresses BLAevoked excitatory responses in PFC neurons. Conversely, $\mathrm{D}_{2 / 4}$ 
(but not $\mathrm{D}_{1}$ ) activity attenuates BLA-evoked inhibition (Floresco and Tse, 2007). Thus, mesocortical DA may exert modulatory control over the balance of excitatory and inhibitory transmission in the BLA-PFC pathway.

As noted, stimulant addiction is associated with impaired regulation of cognitive and emotional processes subserved by amygdala, frontal, and dopaminergic circuits. To explore the neural mechanisms underlying these effects, we assessed how repeated AMPH altered DA modulation of the BLA-PFC pathway in vivo, using extracellular single-unit recordings in anesthetized adult rats. These treatments disrupted $\mathrm{D}_{1} / \mathrm{D}_{2}$ modulation of excitatory/inhibitory responses in the BLA-PFC pathway, suggesting that emotional/ decision-making functions dependent on DA modulation of these circuits may be particularly sensitive to repeated AMPH exposure. Thus, in a second experiment, we assessed how repeated AMPH affected decision making with conditioned punishment, a task dependent on BLA-PFC circuitry and mesocortical DA that assesses the impact that conditioned aversive stimuli exert over the direction of instrumental behavior (Killcross et al., 1997a,b; Floresco and Magyar, 2006).

\section{Materials and Methods \\ Experiment 1: neurophysiological studies}

Animals and AMPH sensitization procedure

Male Sprague Dawley rats (200-225 g; Animal Care Centre, University of British Columbia, Vancouver, BC, Canada) that were at least $60 \mathrm{~d}$ old at the start of the experiment were used. Animals were group housed for 1 week on arrival. One day before the start of injection protocols, animals were individually housed, and all subjects were handled at least twice weekly. They were provided with food and water ad libitum for the duration of the experiment. For every group of rats (typically $6-10$ rats per squad), half were randomly assigned into a group that received either AMPH $(2 \mathrm{mg} / \mathrm{kg}$, mixed in saline; Sigma-Aldrich) or vehicle injections, once every $2 \mathrm{~d}$ for $10 \mathrm{~d}$ (five injections in total). After each injection, rats were placed in operant chambers $(30.5 \times 24 \times 21 \mathrm{~cm}$; Med Associates $)$ enclosed in sound-attenuating boxes. The boxes were equipped with a fan that provided ventilation and masked extraneous noise. The chambers were illuminated by a single $100 \mathrm{~mA}$ house light, and four infrared photobeams were mounted on the sides of each chamber. Locomotor activity was indexed by the number of photobeam breaks that occurred during a session.

After the last injection, rats were left undisturbed for a 2 week drug washout period. Subsequently, rats in the AMPH-treated group (but not the saline-treated group) received an additional challenge dose of AMPH $(2 \mathrm{mg} / \mathrm{kg})$ to test for long-lasting locomotor sensitization. Electrophysiological recordings were performed 1-4 weeks after the final injection (either the last of five saline injections or the AMPH challenge injection) to ensure that any differences between drug-and saline-treated rats could not be attributed to residual drug effects.

\section{Surgery, extracellular recordings, and cell-searching procedures} Rat, weighing $400-550 \mathrm{~g}$ at the time of surgery, were anesthetized with urethane $(1.5 \mathrm{mg} / \mathrm{kg})$ and mounted in a stereotaxic frame, with the incisor bar set at $3.3 \mathrm{~mm}$. Body temperature was maintained at $37^{\circ} \mathrm{C}$ with a temperature-controlled heating pad. In all surgical preparations, the scalp was incised and holes were drilled in the skull overlying the mPFC, the BLA, and, in some preparations, the ventral tegmental area (VTA). After drilling the burr hole, the dura was resected. Concentric bipolar electrical stimulating electrodes (SND-1000; David Kopf Instruments) were implanted into the caudal region of the BLA using the following stereotaxic coordinates (flat skull): BLA electrode, anteroposterior (AP), $-3.0 \mathrm{~mm}$ (bregma); mediolateral (ML), $+5.0 \mathrm{~mm}$; dorsoventral (DV), $-7.2 \mathrm{~mm}$ (cortex) (Paxinos and Watson, 1997). This region was selected for two reasons. First, the majority of the projections from the BLA to the $\mathrm{mPFC}$ originate in the more caudal regions of the BLA (Kita and Kitai, 1990; McDonald, 1991; Condé et al., 1995). Second, projections originating from the mPFC terminate in the more rostral BLA (Sesack et al., 1989;
McDonald et al., 1996). Thus, by placing our electrodes in the caudal portion of the BLA, we would minimize the possibility that BLA-evoked changes in $\mathrm{MPFC}$ neural firing were attributable to antidromic activation of recurrent axon collaterals originating in the mPFC, as we have discussed previously (Floresco and Tse, 2007). In some experiments, we implanted stimulating electrodes in the VTA (AP, $-5.3 \mathrm{~mm}$; ML, 0.8 $\mathrm{mm} ; \mathrm{DV},-7.8 \mathrm{~mm}$ ). All procedures were performed in accordance with the guidelines outlined in the Canadian Council for Animal Care and approved by the Animal Care Committee of the University of British Columbia.

Single-barrel extracellular recording microelectrodes were constructed from 2.0-mm-outer-diameter borosilicate glass capillary tubing using a vertical micropipette puller. The tips of the electrodes were broken back against a glass rode to $\sim 1 \mu \mathrm{m}$ tip diameter and filled with $1 \mathrm{M}$ $\mathrm{NaCl}$ containing $2 \%$ Pontamine sky blue dye. The in vivo impedance of microelectrodes ranged from 5 to $10 \mathrm{M} \Omega$. This impedance range easily detects extracellular action potentials emitted from pyramidal neurons, whereas substantially higher impedance electrodes are required to record from interneurons in the PFC (Tierney et al., 2004).

Recording electrodes were lowered into the mPFC with a hydraulic microdrive (coordinates: $+3.8-2.7 \mathrm{~mm}$ anterior from bregma, $0.6-0.8$ $\mathrm{mm}$ lateral from the midline, $2.2-5.5 \mathrm{~mm}$ ventral from the brain surface). This dorsoventral range passed the electrode through the anterior cingulate, prelimbic, and infralimbic regions of the mPFC. We did not observe any obvious differences in terms of basal firing rates, BLA-evoked changes in firing, or response to pharmacological challenge from neurons that were recorded from more dorsal versus ventral regions of the mPFC. The electrode signal was amplified and filtered $(500-2000 \mathrm{~Hz})$ using an X-Cell3 + microelectrode amplifier (FHC). Action potential data were acquired, discriminated from noise, stored, and analyzed using Spike 2 software (Cambridge Electronic Design) running on an Intelbased personal computer with a data acquisition board interface (micro 1401 mk II; Cambridge Electronic Design).

After a glass microelectrode had been lowered to the dorsal border of the $\mathrm{mPFC}$, a cell-searching procedure began. The microelectrode was lowered incrementally through the $\mathrm{MPFC}$ while electrical stimuli were delivered to the BLA $(800 \mu \mathrm{A})$ at $1.5 \mathrm{~s}$ intervals. Although previous in vitro studies have shown that prolonged low-frequency stimulation can induce long-term depression in the hippocampus (Mulkey and Malenka, 1992), other in vivo studies report that extended bouts of low-frequency stimulation of the hippocampus or the BLA does not produce any reliable change in synaptic efficacy in the mPFC (Burette et al., 1997; Maroun and Richter-Levin, 2003). Cathodal constant current pulses (0.2 ms duration) were delivered to the BLA through an Iso-Flex optical isolator via a Master-8 programmable pulse generator (A.M.P.I.) using the parameters noted below. Once a neuron was encountered, the position of the microelectrode was adjusted to maximize the spike amplitude relative to background noise. We would then stimulate the BLA with at least 50 single pulses to generate peristimulus time histograms (PSTHs). From these histograms, we could determine whether the individual neuron was inhibited, excited, or show no response to BLA stimulation. For neurons that displayed no change in firing in response to BLA stimulation, we did not record data from that cell and continued the cell-searching procedure. For each neuron sampled, we typically obtained at least two PSTHs to ensure stable baseline levels of BLA-evoked changes in firing before dopaminergic manipulations. The average of the two baselines was used to compare with the changes of evoked activities postdrug treatment/ VTA stimulation.

\section{Characterization of BLA-evoked responses and stimulation protocols}

$B L A \rightarrow m P F C(-)$ neurons. As we and others have reported previously (Pérez-Jaranay and Vives, 1991; Ishikawa and Nakamura, 2003; Floresco and Tse, 2007), BLA stimulation evoked one of two distinct types of changes in firing in separate populations of $\mathrm{mPFC}$ neurons. The more commonly observed response was a robust inhibition of neural activity (Floresco and Tse, 2007). We characterized these responses using previously established criteria (Ishikawa and Nakamura, 2003; Floresco and Tse, 2007). Specifically, a cell was considered to be inhibited by BLA 

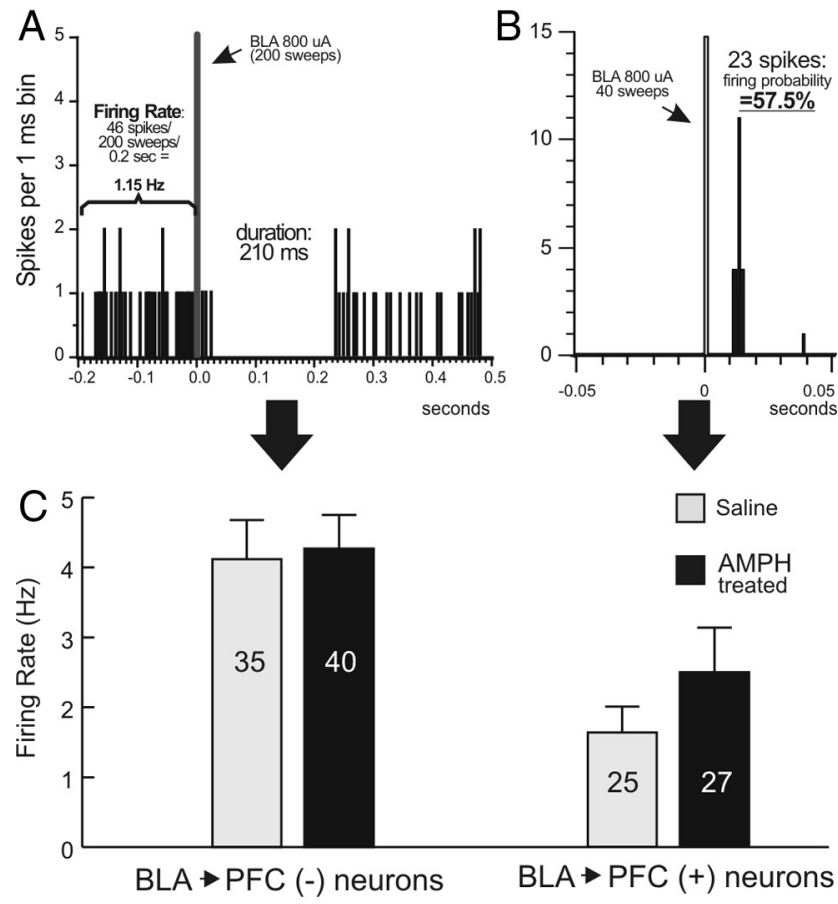

Saline
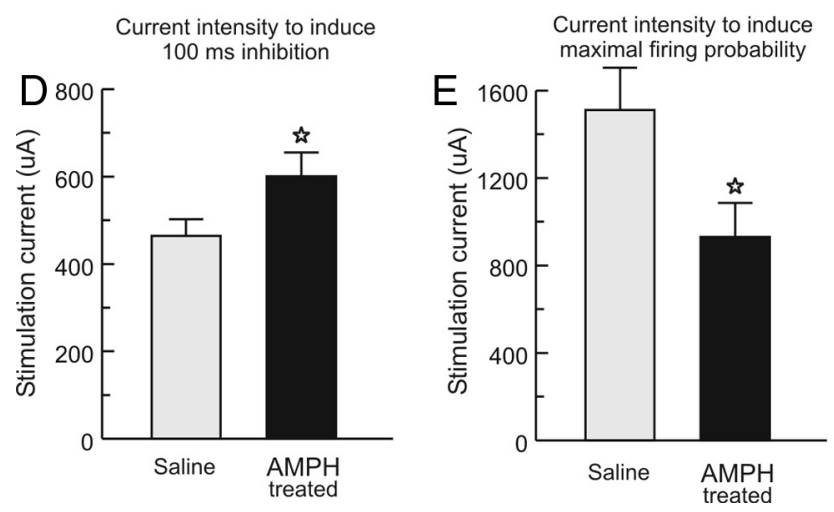

Figure 1. BLA stimulation can induce two distinct responses in separate populations of MPFC neurons (inhibitory and excitatory). Representative PSTH of BLA evoked inhibitory $[\mathrm{BLA} \rightarrow \mathrm{PFC}(-) ; \boldsymbol{A}$ ] and [excitatory BLA $\rightarrow \mathrm{PFC}(+) ; \boldsymbol{B}$ ] responses. $\boldsymbol{C}, \mathrm{BLA} \rightarrow \mathrm{PFC}(-)$ (left) and $\mathrm{BLA} \rightarrow \mathrm{PFC}(+)$ (right) neurons showed comparable basal firing rate between saline- and AMPH-treated rats. Numbers on each bar represent the $n$ for each group. $D$, For $\mathrm{BLA} \rightarrow \mathrm{PFC}(-)$ neurons, higher stimulation currents were required to induce a comparable duration of inhibition in AMPH-treated rats relative to controls. $E$, Conversely, for $\mathrm{BLA} \rightarrow \mathrm{PFC}(+)$ cells, lower stimulation currents were required to induce maximal firing in AMPH-treated rats. is $p<0.05$, between-group difference.

stimulation if it displayed a complete cessation of spontaneous firing that lasted at least $50 \mathrm{~ms}$, with the onset of this inhibition occurring $\sim 30 \mathrm{~ms}$ after BLA stimulation. Hereafter, neurons that displayed this type of response are referred to as $\mathrm{BLA} \rightarrow \mathrm{mPFC}(-)$ neurons. This duration of inhibition is similar to the long-lasting evoked IPSPs recorded from PFC neurons in vitro (Seamans et al., 2001a). The average spontaneous firing rates of these neurons were obtained from the $200 \mathrm{~ms}$ period before BLA stimulation and were calculated using the formula: [(number of spikes observed in the $200 \mathrm{~ms}$ period $\div$ number of sweeps obtained) $\div 200 \mathrm{~ms}]$.

Only neurons that displayed a spontaneous firing rate of $>0.8 \mathrm{~Hz}$ were used in the data analysis. An example of a typical inhibitory response recorded from a BLA $\rightarrow \mathrm{mPFC}(-)$ neuron along with how these parameters were calculated is presented in Figure $1 \mathrm{~A}$.

Once a neuron that was inhibited by BLA stimulation was isolated, single-pulse stimulation was delivered every $1.5 \mathrm{~s}(0.67 \mathrm{~Hz})$. In these experiments, data were compiled using a minimum of 100 sweeps, al- though we typically obtained 150-200 sweeps, and PSTHs were generated online. Stimulation currents were reduced to a minimum level so that the duration of inhibition was at least $100 \mathrm{~ms}$ (overall range, 150$1000 \mu \mathrm{A})$. Once stable baseline levels of BLA-evoked inhibition were achieved, DA transmission was manipulated via systemic administration of AMPH, DA receptor agonists, or stimulation of the VTA (see below). Our primary dependent variable of interest was changes in the duration (in milliseconds) of BLA-evoked inhibition. These values were derived from the PSTHs using previously established parameters (Ishikawa and Nakamura, 2003; Floresco and Tse, 2007). The duration was defined as the longest period when spontaneous firing was completely suppressed within the first $200 \mathrm{~ms}$ after BLA stimulation. The baseline duration of inhibition was compared with postdrug treatment or VTA stimulation, and the percentage change was used as an index of the inhibitory influence that BLA inputs exert over $\mathrm{mPFC}$ neuron firing.

$B L A \rightarrow m P F C(+)$ neurons. A second group of neurons displayed a fast-onset monosynaptic action potential in response to BLA stimulation [hereafter referred to as $\mathrm{BLA} \rightarrow \mathrm{mPFC}(+)$ neurons]. Of these cells, only those that responded with an orthodromic, monosynaptic response and displayed a signal-to-noise ratio of at least 3:1 were used in the data analysis. Evoked firing was characterized as monosynaptic/orthodromic if the response displayed (1) spike jitter of at least $2 \mathrm{~ms}$, (2) a shift in spike latency with increasing current amplitude, and (3) followed pairedpulse stimulation at $50 \mathrm{~Hz}$ [otherwise characterized as polysynaptic (Pirot et al., 1994; Mulder et al., 1997; Floresco and Grace, 2003)]. The majority of these neurons displayed no or very low rates of spontaneous firing, precluding detection of an inhibitory response after the evoked action potential. For neurons displaying some spontaneous activity, the monosynaptic excitatory response was typically followed by a prolonged period of inhibition, as has been reported previously (Pérez-Jaranay and Vives, 1991; Ishikawa and Nakamura, 2003). This is likely attributable to the fact that almost all cortical neurons display a mixed EPSP-IPSP response after afferent pathway stimulation. Despite this effect, these cells were still classified as BLA $\rightarrow \operatorname{mPFC}(+)$ neurons, and we only analyzed the effects of DA manipulations on evoked firing but not the feedforward inhibition.

After establishing that BLA-evoked firing was monosynaptic and orthodromic, stimulation currents were adjusted to submaximal stimulation intensity (range, $100-1000 \mu \mathrm{A}$ ), so that BLA stimulation evoked an action potential $\sim 50-70 \%$ of the time when delivered at $0.25 \mathrm{~Hz}$ (one stimulation every $4 \mathrm{~s}$ ). In each of these experiments, data were compiled using a minimum of 40 sweeps. Evoked firing probabilities were calculated by dividing the number of evoked spikes by the number of pulses delivered, as has been described previously (Floresco and Grace, 2003; Floresco and Tse, 2007). Once stable baseline levels of evoked-firing were achieved, DA transmission was manipulated via systemic administration of AMPH, DA receptor agonists, or stimulation of the VTA. Changes in BLA-evoked firing probabilities were used as an index of changes in the excitatory influence that BLA inputs exert over mPFC neuron firing. The spontaneous firing rates for these neurons were calculated in the same manner as was done for BLA $\rightarrow \operatorname{mPFC}(-)$ neurons. An example of a $\mathrm{BLA} \rightarrow \mathrm{mPFC}(+)$ neuron and how firing probabilities were calculated is presented in Figure $1 B$.

\section{Systemic administration of DA agonists}

To ascertain how repeated AMPH exposure altered DA modulation of BLA-evoked changes in PFC neural activity, separate experiments used intravenous administration of AMPH or DA agonists selective for $\mathrm{D}_{1}, \mathrm{D}_{2}$, and $\mathrm{D}_{4}$ receptors. Separate groups of rats that received either repeated saline or AMPH injections were implanted with intravenous jugular catheters, consisting of tubing attached to a $1 \mathrm{ml}$ syringe. In these studies, each rat received only one drug injection, and we only obtained data from one neuron per rat. For each type of response, stimulation intensities were adjusted, stable baseline levels of BLA-evoked inhibition or excitation were established, after which drugs were administered. We would then wait 5 min after drug injection before stimulating the BLA again using the same current intensity that was used during baseline sampling. For BLA $\rightarrow \operatorname{mPFC}(-)$ neurons, we would typically record two to three sessions of 100-200 sweeps before and after drug administration, whereas 
for BLA $\rightarrow \mathrm{mPFC}(+)$ neurons, we would typically sample evoked firing over $40-150$ sweeps.

We tested the effects of acute AMPH $(0.5 \mathrm{mg} / \mathrm{kg})$ on both BLAevoked inhibition and excitation of mPFC neurons. In addition, we tested the effects of the selective $\mathrm{D}_{2}$ agonist bromocriptine $(0.5 \mathrm{mg} / \mathrm{kg}$; Sigma-Aldrich) and the selective $\mathrm{D}_{4}$ agonist PD 168,077 ( $N$-[[4-(2cyanophenyl)piperazin-1-yl]methyl]-3-methylbenzamide) $(1.0 \mathrm{mg} / \mathrm{kg}$; Tocris Biosciences) on BLA-evoked inhibition, and the selective $\mathrm{D}_{1}$ receptor agonist SKF81297 (6-chloro-2,3,4,5-tetrahydro-1-phenyl-1 $\mathrm{H}$ 3-benzazepine hydrobromide) $(0.5 \mathrm{mg} / \mathrm{kg}$; Tocris Biosciences) on BLAevoked excitatory responses. All drugs were dissolved in physiological saline, sonicated until dissolved, and protected from light, with the exception of bromocriptine, which was dissolved in a small volume of DMSO (20\%) and diluted with saline. The concentrations of these solutions were set so that injection volumes would range between 0.15 and $0.30 \mathrm{ml}$. The doses of these drugs were chosen from previous studies that have shown alterations in either behaviors or neural activity in DA terminal regions when administered systemically at these doses (Maslowski and Napier, 1991; Nayak and Cassaday, 2003; Hotte et al., 2006). Furthermore, we have shown that these doses of the $\mathrm{D}_{1}$ or the $\mathrm{D}_{2} / \mathrm{D}_{4}$ agonists were effective at attenuating BLA-evoked excitatory or inhibitory responses, respectively, in mPFC neurons of normal animals (Floresco and Tse, 2007).

\section{VTA modulation of BLA-evoked inhibition and excitation of MPFC neurons}

$B L A \rightarrow m P F C(-)$ neurons. For these cells, BLA stimulation intensities were adjusted to evoke a complete cessation of firing with an onset of $\sim 30 \mathrm{~ms}$ and a duration of 150-200 ms. Baseline levels of evoked inhibition were assessed over two to three samples of 100-200 sweeps delivered at $0.67 \mathrm{~Hz}$ to ensure response stability. Once stable baseline levels of evoked-inhibition were obtained, the VTA was activated in a burst pattern $(20 \mathrm{~Hz}$ train of four pulses, $700 \mu \mathrm{A}) 50 \mathrm{~ms}$ before single-pulse stimulation of the BLA. This combined pattern of stimulation was delivered every $10 \mathrm{~s}$ over 50 sweeps. As we have observed previously (Floresco and Tse, 2007), VTA stimulation by itself often caused a robust, inhibition of spontaneous firing that overlaps with the period of inhibition induced by BLA stimulation. Thus, we were unable to assess the shortacting ( $<200 \mathrm{~ms}$ ) effects of VTA stimulation on BLA-evoked inhibition. To assess longer-lasting effects (2-10 min) of VTA stimulation on BLAevoked inhibition of firing, we again stimulated the BLA with single pulses 1 min after the last VTA burst. Current intensities and stimulation frequency were kept constant across baseline and test sweeps (two samples, 100-200 sweeps each). In experiments in which more than one neuron was recorded from a rat, we waited at least 30 min between bouts of VTA stimulation before resuming cell-searching procedures.

$B L A \rightarrow m P F C(+)$ neurons. For these experiments, BLA stimulation intensities were adjusted to evoke an action potential $\sim 60-75 \%$ of the time after single-pulse BLA stimulation delivered at $0.25 \mathrm{~Hz}$. Similar to $\mathrm{BLA} \rightarrow \mathrm{mPFC}(-)$ cells, we typically obtained two sets of baseline data to ensure cell stability before providing any manipulation. Once baseline firing probabilities were obtained, burst stimulation of the VTA was administered 50 ms before stimulation of the BLA. We used a minimum of 40 sweeps to compile the data for all experiments assessing the effects of VTA stimulation on BLA-evoked excitatory responses.

\section{Histology}

At the end of each experiment, the recording site in the mPFC was marked via iontophoretic ejection of Pontamine sky blue dye from the tip of the recording electrode ( $30 \mu \mathrm{A}$ constant positive current for $20-30$ $\min )$. Iron deposits were made in stimulation sites by passing direct current (150 $\mu \mathrm{A}$ for $15 \mathrm{~s}$ ) through the stimulating electrode. After dye ejection, brains were removed and fixed in Formalin containing $0.1 \%$ potassium ferricyanide for at least $24 \mathrm{~h}$. Brains were then sectioned into $50 \mu \mathrm{m}$ coronal slices, mounted, and stained with cresyl violet $(2 \%)$ to enable histological determination of recording and stimulating electrode sites.

\section{Data analysis}

Data from studies using systemic administration of DA agonists were analyzed with a three-way between/within-subjects factorial ANOVA, with treatment group (repeated AMPH vs saline) and acute drug types (i.e., DA agonist or vehicle) as two between-subjects factor and sample (baseline vs postdrug administration) as a within-subjects factor. Data from studies using VTA stimulation were analyzed using repeatedmeasures ANOVA, with sample (i.e., baseline vs post-DA manipulation) as a within-subjects factor and treatment group as a between-subjects factor.

\section{Experiment 2: behavioral studies}

\section{Subjects, apparatus, and behavioral training}

Twenty-seven male rats $(280-350 \mathrm{~g})$ were food restricted to $85 \%$ of their free feeding weight by providing them with $20-25 \mathrm{~g}$ of chow per day. Four operant chambers $(30.5 \times 24 \times 21 \mathrm{~cm}$; Med Associates $)$ housed in sound-attenuating boxes were used. Each chamber was fitted with two retractable levers located on each side of a central food cup in which reinforcement ( $45 \mathrm{mg}$; Bioserv) was delivered by a pellet dispenser. A 100 $\mathrm{mA}$ stimulus light was located above each lever. The floors consisted of 5 -mm-diameter steel rods spaced $1.6 \mathrm{~cm}$ apart that were connected to a shock generator/scrambler. Auditory stimuli were delivered via a speaker located on the wall opposite the levers, connected to a programmable audio generator. Each chamber was illuminated by a single, $100 \mathrm{~mA}$ house light located top-center opposite of the levers.

We used a protocol similar to that described by Killcross et al. (1997a) (see Fig. 8 A). Over daily, 30 min sessions, rats were trained to respond on both levers for food. Over a period of $\sim 2$ weeks, the schedules of reinforcement on each lever were increased from a variable interval (VI) $15 \mathrm{~s}$ schedule (i.e., approximately every $15 \mathrm{~s}$, the lever would become active, and the next press would deliver food), then on a VI $30 \mathrm{~s}$, and finally a VI $60 \mathrm{~s}$ schedule. The schedule on each lever was independent of the other, and a $2 \mathrm{~s}$ changeover delay was also imposed (i.e., the first response that could be reinforced after switching from one lever to the other had to occur at least $2 \mathrm{~s}$ after the last response on the preswitching lever). To remove any side biases, the VI on each lever increased or decreased from VI $60 \mathrm{~s}$ according to the ratio of pressing on that lever relative to the overall rate of pressing on both levers. This rapidly equalized responding on the two levers, and all subsequent training was conducted using fixed VI 60 s intervals on both levers.

Subsequently, punishment training was conducted over daily, $30 \mathrm{~min}$ sessions in which food pellets were delivered on VI $60 \mathrm{~s}$ schedules as before. However, responses on one lever now delivered a $10 \mathrm{~s}$, complex stimuli consisting of a $5 \mathrm{kHz}$ tone and illumination of both stimulus lights, and the other a $10 \mathrm{~s}, 500 \mathrm{~Hz}$ tone and flashing house light. These stimuli were delivered response contingently according to concurrent and independent VI $120 \mathrm{~s}$ schedules, again with a $2 \mathrm{~s}$ changeover delay, with the additional constraint that both stimuli could not be activated at the same time. The final 1.0 s of one of these stimuli (the CS+) coincided with the delivery of a $1.0 \mathrm{~s}$ footshock, and the other (the CS-0) had no programmed consequences. Using these schedules, rats typically received $\sim 25$ pellets and 5-12 presentations of each conditioned stimulus (CS), even with low response rates. The assignment of shock to stimulus, and stimulus to lever, was counterbalanced and remained constant throughout training. Over sessions, animals came to bias their responding away from the lever delivering the $\mathrm{CS}+$ and footshock and toward the lever producing the neutral CS-0. Over the duration of training, the level of footshock was adjusted based on each individual animal's performance (initial intensity, $0.35 \mathrm{~mA}$ ) until the animal began bias responding away from the shock-producing lever (final range, 0.6-1.5 mA). Rats were trained in this manner for $\sim 25 \mathrm{~d}$. At this point, the group displayed a discrimination ratio of $>85 \%$ (i.e., $<15 \%$ of their responses were directed toward the lever producing the $\mathrm{CS}+$ and shock).

Animals were subsequently matched for performance with respect to the average discrimination ratio, total lever presses, and shock intensity over the last $2 \mathrm{~d}$ of training and assigned to either a repeated AMPH or saline treatment group. They then received five injections of $2 \mathrm{mg} / \mathrm{kg}$ AMPH in a manner identical to that used for the neurophysiological studies, followed by a $7 \mathrm{~d}$ drug washout period. 
Retraining and extinction tests of conditioned punishment

Each rat was retrained on the punishment task with the same individual shock intensities used for that rat before drug/saline treatment. Training continued until a rat again displayed a discrimination ratio of $85 \%$ for at least 2 consecutive days, after which it was subjected to extinction tests of conditioned punishment. These testing sessions were identical to the regular punishment training (i.e., both food pellets and the complex stimuli were delivered on their respective schedules) but with the key exception that no footshocks were delivered during this test. Thus, these extinction tests of conditioned punishment examined the impact solely of the secondary negative reinforcement (the aversive $\mathrm{CS}+$ ) on the direction of instrumental behavior.

Each conditioned punishment test was part of a $2 \mathrm{~d}$ sequence. On the day after their final training session, a rat received a $30 \mathrm{~min}$ baseline lever-pressing session with both levers delivering food as normal, but no CSs were delivered. This procedure was instituted for two reasons. First, these baseline sessions were intended to reduce any simple position bias that may have developed during training (if a rat displayed a bias $>60 \%$ toward a lever after the initial baseline session, another identical session was given the next day). Second, and more importantly, data from the baseline sessions were used in the statistical analyses, wherein the number of responses on each lever during baseline sessions in the absence of CS delivery were compared with the number of responses on the same lever made on conditioned punishment test days, when the CS + and CS-0 were delivered (without shocks). On the day after the baseline session, the rat received the critical 30 min extinction session of conditioned punishment as described above. After this test day, the rat received another baseline training day (pellet delivery only), before being retrained to criterion according to their original training allocation of reinforcer, stimulus, and lever. Each rat was subjected to two such test sequences. For one of these tests (presented in a counterbalanced manner), the left/right position of the levers delivering the CS + and CS- 0 was the reversed from training, to reduce the possibility that any response bias in extinction was attributable to a position bias rather than of the conditioned punishing properties of the CS + . The data from these two tests were averaged for the final analysis.

Two main dependent variables collected during conditioned punishment test days were analyzed. First was the proportional number of responses on each lever compared with the number of responses on that lever made during baseline sessions. This value was calculated by dividing the number of responses on the CS + or CS-0 lever on conditioned punishment test days by the number of responses on the same lever made during baseline sessions. Differences between the proportions of responding on each lever indexed the preference an animal had for each lever. Thus, a value of 1.0 indicates that a rat responded as frequently on a particular lever on conditioned punishment test days as it did on baseline days when no CS was presented, whereas lower values indicated a reduced preference for that lever. The second measure was conditioned suppression of lever pressing induced by the CS + and CS-0, used as an index conditioned fear. These values were obtained by dividing the response rates during the presentation of each stimulus by the overall rate when stimuli were not presented, using the following formula: response rate during CS/[(response rate during CS) + (response rate in absence of CS)]. Thus, a value of 0 indicates complete suppression of responding during presentation of the CS, and a value of 0.5 indicates no suppression of lever pressing.

\section{Results}

\section{Experiment 1: neurophysiological studies}

\section{Repeated AMPH treatment}

Locomotion data was analyzed from 95 rats from which stable neurophysiological data were obtained (repeated AMPH, $n=48$; saline, $n=47)$. Rats receiving repeated AMPH showed a significant $(p<0.01)$ increase in photobeam breaks from the first $(815 \pm 38)$ to the fifth $(937 \pm 48)$ injection, whereas salinetreated rats actually decreased activity over this period (first injection, $419 \pm 19$; fifth injection, $334 \pm 20$; group $\times$ day interaction, $\left.F_{(4,372)}=6.18, p<0.01\right)$. Moreover, rats in the
AMPH group continued to display a sensitized locomotor response relative to their first injection after AMPH challenge administered 1 week after the last injection (967 $\pm 71, p<0.01$ relative to first injection).

\section{Spontaneous and BLA-evoked activity in $M P F C$ neurons in} saline- and AMPH-treated rats

Data obtained from a total of $127 \mathrm{mPFC}$ neurons are reported here. Of these, 67 neurons were recorded from 48 AMPH-treated rats and 60 neurons from 47 saline-treated (control) rats. We did not observe any reliable between-group differences in spontaneous firing rates of either population of neurons [BLA $\rightarrow$ $\operatorname{mPFC}(-)$ neurons, $t_{(73)}=0.208$, NS (Fig. $1 C$, left); BLA $\rightarrow$ $\operatorname{mPFC}(+)$ neurons, $t_{(50)}=0.90$, NS (Fig. $1 C$, right)]. However, we noticed that, in AMPH-treated rats, higher stimulation currents were required to evoke inhibitory responses that were comparable in duration with those observed in control animals. To directly compare this difference between groups, the data were normalized by dividing the duration of inhibition by the stimulation current used for each animal (multiplied by 100), to obtain an estimate of the average current required to evoke $100 \mathrm{~ms}$ of inhibition. Analysis of these data confirmed that mPFC neurons recorded from AMPH-treated rats were less sensitive to the inhibitory effects of BLA stimulation than controls $\left(t_{(73)}=2.07\right.$, $p<0.05$ ) (Fig. 1D). Conversely, when we conducted a similar response/current analysis for $\mathrm{BLA} \rightarrow \mathrm{mPFC}(+)$ neurons, we observed that maximal excitatory responses could be evoked with lower stimulation currents in AMPH-treated versus control rats $\left(t_{(73)}=2.37, p<0.05\right)$ (Fig. $1 E$ ). This suggests that, after repeated AMPH treatment, the excitatory influence of BLA inputs on mPFC neurons was enhanced, while at the same time, the inhibitory influence of the BLA on populations of mPFC cells was reduced. This observation is consistent with previous reports that repeated psychostimulant exposure leads to (1) a general increase in excitability of mPFC pyramidal neurons (Peterson et al., 2000; Parsegian et al., 2011) and (2) a reduction in mPFC GABAergic interneurons in the mPFC (Morshedi and Meredith, 2007).

Representative locations of $\mathrm{mPFC}$ neurons recorded in this study and stimulation electrodes are presented in Figure 2.

\section{Disruptions in DA modulation of BLA $\rightarrow$ mPFC inhibitory responses induced by repeated $A M P H$}

Increasing mesocortical DA activity attenuates BLA-evoked inhibition of mPFC neurons in normal animals (Floresco and Tse, 2007). To assess changes in dopaminergic modulation of BLA $\rightarrow$ $\mathrm{mPFC}(-)$ neurons induced by repeated $\mathrm{AMPH}$, separate groups of AMPH-treated and control rats received intravenous administration of acute $\mathrm{AMPH}$, the $\mathrm{D}_{2}$ receptor agonist (bromocriptine), or the $\mathrm{D}_{4}$ agonist (PD 168,077). We also included a control group that received acute intravenous saline treatment to confirm that any changes in BLA-evoked inhibition were not attributable to repeated stimulation of the BLA. Analysis of changes in the duration of BLA-evoked inhibition induced by these different treatment yielded a significant sample $\times$ drug $\times$ treatment group interaction $\left(F_{(3,44)}=3.65, p<0.05\right)$. A similar result was obtained when we analyzed the data in terms of percentage change from baseline (drug $\times$ treatment interaction, $F_{(3,44)}=3.60, p<0.05$ ). Importantly, acute saline injections did not alter the duration of BLA-evoked inhibition relative to baseline in either treatment group [AMPH-treated $(n=5)$ : baseline, $148.0 \pm 13 \mathrm{~ms}$; after injection, $158.6 \pm 23 \mathrm{~ms}$; controls $(n=5): 124.0 \pm 13 \mathrm{~ms}$; after injection, $132.2 \pm 6 \mathrm{~ms}$ ]. Thus, in both groups, repeated singlepulse stimulation of the BLA did not lead to changes in BLAevoked inhibition of MPFC neurons over time. 


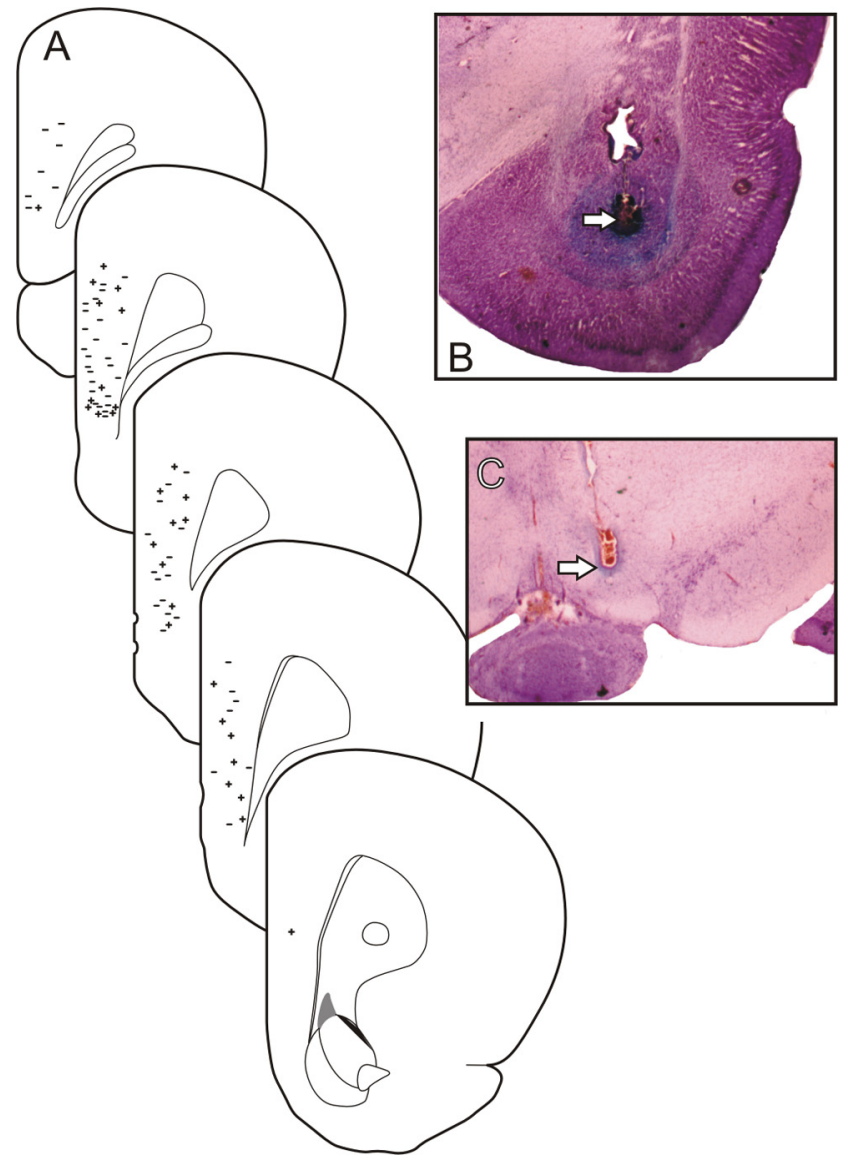

Figure 2. Histology. $A$, Schematic coronal slices of the $\mathrm{MPFC}$ showing representative locations in which BLA-evoked inhibitory $(-)$ and excitatory $(+)$ responses were observed. $\boldsymbol{A}$ displays photomicrographs of representative placements of stimulating electrodes at the BLA (B) and the VTA (C). Arrows highlight the location of the stimulating electrode tips.

Administration of acute AMPH (0.5 mg/kg, i.v.) in control rats $(n=10)$ induced a pronounced and significant $(p<0.05)$ decrease in BLA-evoked inhibition of mPFC neurons (Fig. $3 A$ ). In stark contrast, acute $\mathrm{AMPH}$ treatment in rats that received repeated AMPH $(n=10)$ was without effect on this measure (Fig. $3 A$ ). Thus, repeated AMPH exposure induces an apparent tolerance to the effects of acute AMPH on modulation of inhibitory transmission in the BLA $\rightarrow$ PFC pathway.

DA attenuates BLA-evoked inhibition of $\mathrm{mPFC}$ neural firing via both $\mathrm{D}_{2}$ and $\mathrm{D}_{4}$ receptors (Floresco and Tse, 2007), putatively as a result of a reduction in GABA-mediated inhibitory potentials on mPFC pyramidal neurons (Seamans et al., 2001a; Wang et al., 2002; Kroener and Lavin, 2010). Thus, subsequent experiments used administration of $\mathrm{D}_{2}$ or $\mathrm{D}_{4}$ receptor-selective agonists. Administration of the $\mathrm{D}_{2}$ agonist bromocriptine $(0.5 \mathrm{mg} / \mathrm{kg})$ significantly $(p<0.05)$ reduced the duration of BLA-evoked inhibition in control rats $(n=5)$, as we have reported previously (Floresco and Tse, 2007) (Figs. 3B, 4, top). However, this $\mathrm{D}_{2}$ agonist was completely ineffective at altering BLA-evoked inhibition in AMPH-treated rats $(n=6)$ (Figs. $3 B, 4$, bottom). In contrast, activation of $\mathrm{D}_{4}$ receptors with $\mathrm{PD} 168,077$ was equally effective at attenuating BLA-evoked inhibition of MPFC neurons in both AMPH-treated $(n=5)$ and control animals $(n=5)$ (Fig. $3 C)$. Notably, acute administration of any of these drugs did not induce any between-group differences on the basal firing rates of mPFC neurons $\left(F_{(3,44)}=1.43\right.$, NS). Thus, repeated AMPH exposure induced a selective perturbation of $\mathrm{D}_{2}$ but not $\mathrm{D}_{4}$ receptor
- BLA-evoked inhibitory responses in MPFC neurons -
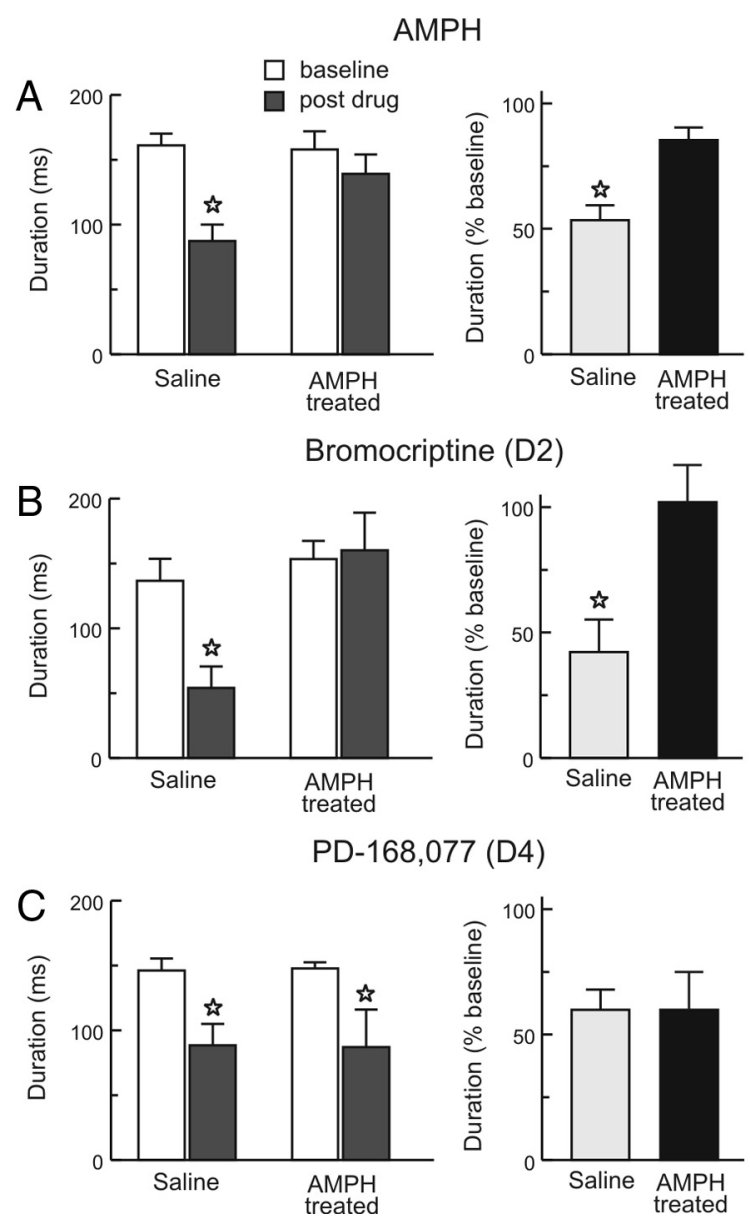

Figure 3. Changes in BLA-evoked inhibition induced by DA agonists. Left panels represent mean \pm SEM duration of evoked inhibition under baseline conditions (white bars) and after treatment with DA agonists (gray bars); $\_<0.05$, difference relative to baseline. Right panels are these data expressed as a percentage change from baseline; $\downarrow p<0.05$, between-group difference. $\boldsymbol{A}$, Treatment with AMPH $(0.5 \mathrm{mg} / \mathrm{kg}$, i.v.) significantly attenuates BLA-evoked inhibition in control rats ( $n=10$ cells, 10 rats), but this effect was abolished in rats that had received repeated AMPH ( $n=10$ cells, 10 rats). $\boldsymbol{B}$, Treatment with the $D_{2}$ receptor agonist bromocriptine $(0.5 \mathrm{mg} / \mathrm{kg}$, i.v.) also attenuated BLA-evoked inhibition in control rats $(n=5$ cells, 5 rats) but not in AMPH treated rats ( $n=6$ cells, 6 rats), suggesting that these treatments induce a disruption in $D_{2}$ receptor signaling. $C$, Treatment with the $D_{4}$ receptor agonist PD $168,077(1.0 \mathrm{mg} / \mathrm{kg}$, i.v.) was effective in reducing BLA-evoked inhibition in both groups ( $n=$ 5 cells, 5 rats per group).

functioning, which in turn hampers dopaminergic attenuation of BLA-evoked inhibition of mPFC neurons. The lack of effect of repeated AMPH treatment on $\mathrm{D}_{4}$ receptor modulation is consistent with previous findings showing that $\mathrm{D}_{4}$ receptor binding in the forebrain is unchanged after AMPH sensitization (Zhang et al., 2000). Furthermore, the selective disruption of $\mathrm{D}_{2}$ versus $\mathrm{D}_{4}$ modulation of BLA-evoked inhibition of $\mathrm{mPFC}$ neurons may be related to differences in the second-messenger pathways through which these receptors exert their effects $\left(D_{2}\right.$ PLC vs $\mathrm{D}_{4}$ PKA) (Wang et al., 2002; Trantham-Davidson et al., 2004) or differential expression of these receptors on pyramidal versus parvalbumin-positive GABAergic interneurons (de Almeida and Mengod, 2010).

In a separate group of rats, we assessed the effects of burst stimulation of the VTA on $\mathrm{BLA} \rightarrow \operatorname{mPFC}(-)$ neurons. Analysis of these data revealed a significant treatment $\times$ sample interaction $\left(F_{(1,16)}=6.43, p<0.05\right)($ Fig. $5 A)$. Replicating our previous 


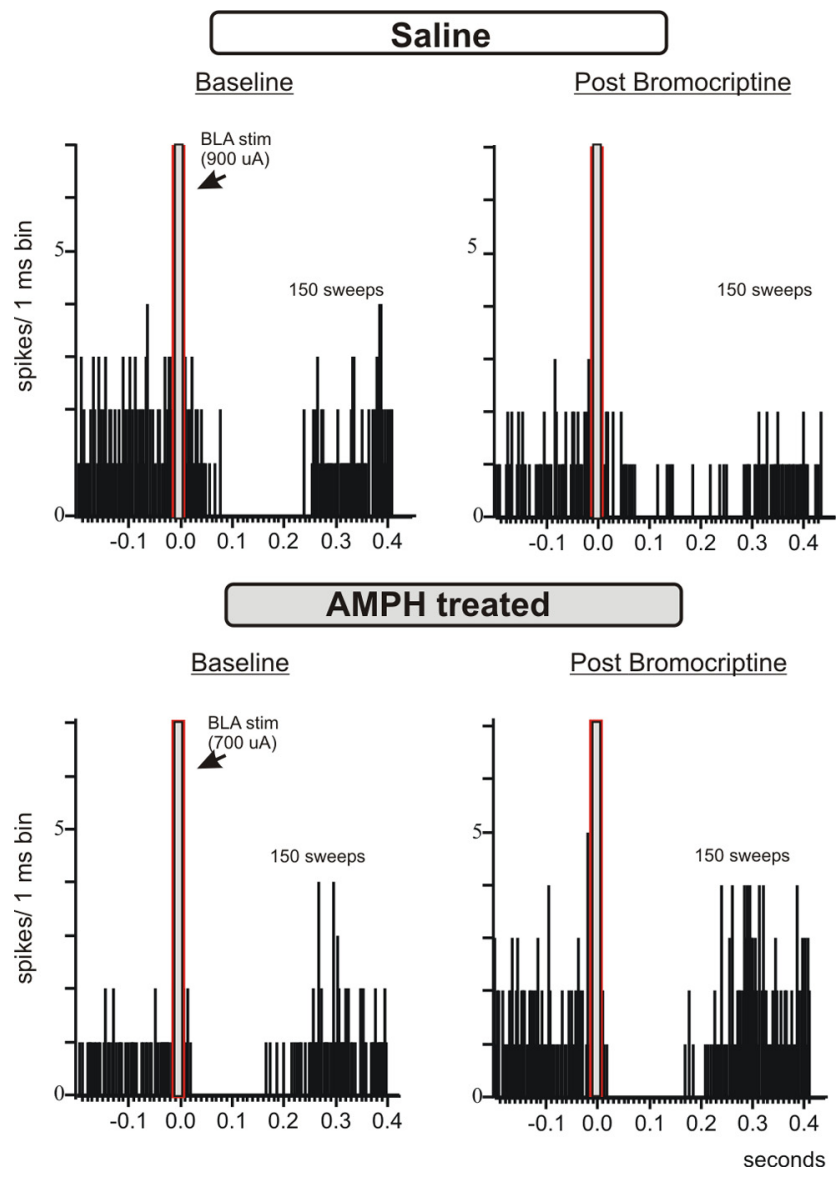

Figure 4. Representative PSTH illustrating the effect of $D_{2}$ receptor stimulation on BLA $\rightarrow$ PFC( - ) in control and AMPH-treated rats. Each histogram is compiled from firing data obtained over 150 single-pulse stimulations (sweeps) of the BLA. Stimulation of $D_{2}$ receptors reduced the duration of inhibition induced by BLA stimulation in this neuron recorded from a saline-treated rat (top). However, similar treatments were ineffective at altering BLA-evoked inhibition in a neuron recorded from a rat that had received repeated AMPH (bottom).

observations (Floresco and Tse, 2007), repeated burst stimulation of the VTA in control rats $(n=8)$ attenuated BLA-evoked inhibition, with this effect persisting for $\sim 10 \mathrm{~min}$ (two samples) after VTA stimulation was terminated. Again, this effect was not observed in AMPH-treated rats $(n=10)$. In this experiment, the baseline levels of BLA-evoked inhibition were of longer duration in the control group relative to AMPH-treated rats. However, analysis of data from a subset of neurons that were matched for comparable levels of inhibition across groups also revealed that VTA stimulation was effective at reducing BLA-evoked inhibition in controls but not AMPH-treated animals [controls $(n=6)$ : baseline, $144 \pm 21 \mathrm{~ms}$; post-VTA stimulation, $79 \pm 26 \mathrm{~ms}$; AMPHtreated $(n=8)$ : baseline, $146 \pm 5 \mathrm{~ms}$; post-VTA stimulation, $138 \pm$ $17 \mathrm{~ms}$; treatment $\times$ sample interaction, $\left.F_{(1,12)}=4.68, p=0.05\right]$. These findings confirm that the ability of endogenous DA to modulate inhibitory transmission in the BLA-mPFC pathway is also disrupted by repeated AMPH exposure.

For the VTA stimulation experiments, we noticed another difference between groups. Specifically, in control rats, $\mathrm{mPFC}$ neurons increased their average firing rate over the course of the 50 VTA bursts compared with the rats recorded during baseline sweeps (baseline, $2.4 \pm 0.7 \mathrm{~Hz}$; VTA stimulation, $4.9 \pm 1.7 \mathrm{~Hz}$ ), as has been reported by other groups (Au-Young et al., 1999). However, this effect was not observed in AMPH-treated rats (baseline, $3.1 \pm 0.6 \mathrm{~Hz}$; VTA stimulation, $2.8 \pm 0.7 \mathrm{~Hz}$ ). We analyzed these data in terms of percentage change versus baseline, and this analysis confirmed that the two groups differed significantly on this measure $\left(t_{(16)}=2.28, p<0.05\right)$ (Fig. $5 B$ ). Thus, repeated $\mathrm{AMPH}$ exposure also disrupts the excitatory effect that repetitive VTA bursts exerts on the spontaneous firing of $\mathrm{mPFC}$ neurons.

Disruptions in DA modulation of BLA $\rightarrow$ mPFC excitatory responses induced by repeated $A M P H$

Activation of $\mathrm{D}_{1}$, but not $\mathrm{D}_{2}$ or $\mathrm{D}_{4}$, receptors attenuates monosynaptic excitatory responses in mPFC neurons evoked by BLA stimulation (Floresco and Tse, 2007). We assessed the efficacy of dopaminergic modulation of BLA $\rightarrow$ PFC evoked firing in AMPH-treated and control rats with intravenous administration of acute AMPH or the $\mathrm{D}_{1}$ receptor agonist SKF81297.

Figure $6 A$ displays the effect of acute AMPH $(0.5 \mathrm{mg} / \mathrm{kg})$ on BLA-evoked firing of mPFC neurons. This treatment reduced the evoked firing probability by $\geq 20 \%$ in nine of nine (100\%) neurons tested in control animals, with a parametric analysis of these data confirming this effect to be statistically significant $(p<$ 0.05). However, similar treatment in AMPH-treated rats revealed a blunted and less reliable response, in that acute AMPH did not induce a significant decrease in evoked firing compared with baseline. In this group, acute AMPH attenuated BLA-evoked firing in only four of eight (50\%) mPFC neurons. Parametric analysis of these data with a two-way ANOVA yielded a treatment group $\times$ sample interaction that only trended toward statistical significance $\left(F_{(1,15)}=3.27, p=0.09\right)$. However, exploratory oneway ANOVAs did reveal that acute AMPH induced a significant suppression of BLA-evoked firing in control $\left(F_{(1,8)}=34.72, p<\right.$ $0.001)$ but not in AMPH-treated rats $\left(F_{(1,7)}=2.29, \mathrm{NS}\right)$. An even more pronounced difference between groups was observed after treatment with SKF81297 (treatment group $\times$ sample interaction, $\left.F_{(1,10)}=16.84, p<0.005\right)$. Simple main effects analysis confirmed that, in control rats, the $\mathrm{D}_{1}$ agonist induced a significant $(p<0.001)$ inhibition of BLA-evoked firing, an effect observed in six of six (100\%) mPFC neurons tested (Figs. 6B, 7, top). However, in AMPH-treated rats, $D_{1}$ receptor stimulation failed to induce a significant suppression of evoked firing $(p>$ $0.50)$, with only one of six neurons tested (17\%) displaying any discernable reduction in the BLA-evoked firing probability (Figs. $6 B, 7$, bottom). Thus, mirroring the phenomenon observed in $\mathrm{BLA} \rightarrow \mathrm{mPFC}(-)$ neurons, repeated AMPH exposure leads to a disruption of dopaminergic modulation of BLA-evoked monosynaptic excitatory responses in mPFC neurons. This effect appears attributable in part to a disruption of $\mathrm{D}_{1}$ receptor signaling.

In separate groups of AMPH-treated and control rats, we tested the effects of VTA stimulation on BLA-evoked firing. Analysis of these data revealed a significant effect of sample $\left(F_{(1,11)}=\right.$ $44.56, p<0.001)$ but not treatment group $\times$ sample interaction $\left(F_{(1,11)}=1.56, \mathrm{NS}\right)$. As displayed in Figure $6 C$, burst stimulation of the VTA $50 \mathrm{~ms}$ before single-pulse stimulation of the BLA significantly suppressed evoked firing of mPFC neurons recorded from control and AMPH-treated rats. Notably, VTA stimulation suppressed BLA-evoked firing (i.e., $\geq 20 \%$ reduction in firing probability) in $100 \%$ of neurons recorded from control rats $(n=$ $6)$, whereas this effect was only observed in $83 \%$ of neurons recorded from AMPH-treated rats $(n=7)$. Thus, increased $\mathrm{D}_{1}$ receptor tone normally suppresses BLA-evoked firing of $\mathrm{mPFC}$ neurons, with this effect being disrupted by repeated AMPH exposure. However, the suppressive effect of phasic VTA activity [mediated by both DA and GABA transmission (Pirot et al., 


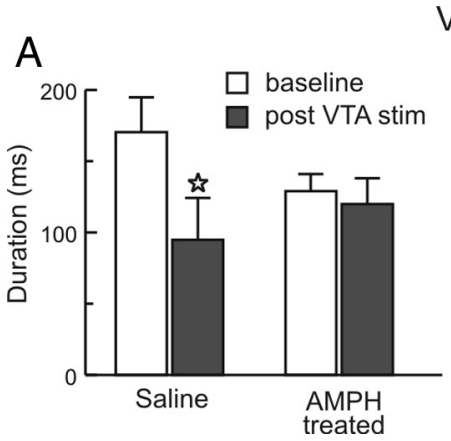

VTA stimulation

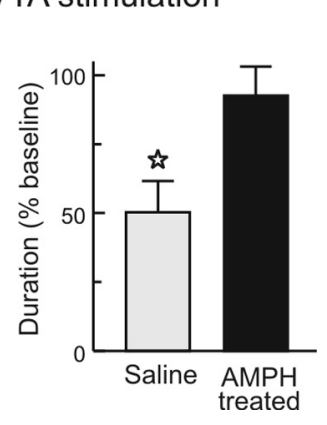

$\mathrm{B}$

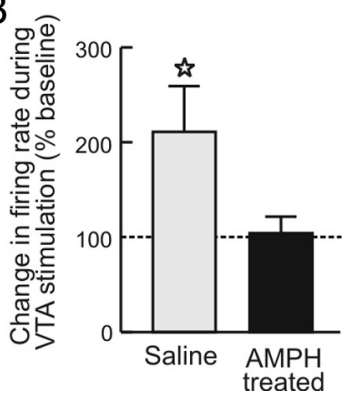

Figure 5. Effects of repetitive burst stimulation of VTA on BLA-evoked inhibition of $\mathrm{mPFC}$ neurons. $A$, VTA stimulation leads to an attenuation of BLA-evoked inhibition in saline-treated ( $n=8$ cells, 4 rats) but not AMPH-treated rats ( $n=10$ cells, 7 rats). All conventions same as Figure $3 . \boldsymbol{B}$, Repeated burst stimulation of the VTA also increased the spontaneous firing rate of these neurons in saline-treated but not AMPH-treated animals. $\star_{p}<0.05$, between-group difference.

1992)] on BLA-evoked firing of mPFC neurons remains somewhat spared.

\section{Experiment 2: behavioral studies}

Our neurophysiological findings revealed that repeated AMPH disrupted $D_{1}$ and $D_{2}$ receptor modulation of BLA input to the mPFC. One prediction that arises from these data is that repeated AMPH exposure may also disrupt certain cognitive/emotional functions dependent on BLA-PFC circuitry and mesocortical $D_{1} / D_{2}$ receptor activity. The use of conditioned aversive stimuli to guide instrumental action is one such function mediated by this circuitry, which in rats can be assessed with a conditioned punishment procedure. This task requires discrimination between options to minimize the presentation of secondary negative reinforcement, similar to many decision-making tasks used in humans. Lesions of the BLA (Killcross et al., 1997b) or blockade of $m P F C D_{1}$ or $D_{2}$ receptors (Floresco and Magyar, 2006) disrupts the impact that conditioned aversive stimuli (a footshock-associated CS) exert over the direction of instrumental responding, suggesting that BLA-PFC communication may mediate this form of decision making (Coutureau et al., 2000).

During the initial stages of punishment training (Fig. $8 \mathrm{~A}$ ), rats rapidly acquired a pavlovian association between the CS + and footshock. By the third day of training, all rats showed robust and discriminative suppression of lever pressing during presentation of the CS+ (suppression ratio, $0.10 \pm 0.02$ ) relative to the CS-0 $\left(0.48 \pm 0.03 ; t_{(26)}=12.23, p<0.001\right)$. However, acquisition of an instrumental response bias away from the lever producing the $\mathrm{CS}+/$ shock was slower to develop. This is consistent with previous findings that lever-press-shock learning is slower than CSshock learning (Bolles et al., 1975; Lee et al., 2005), which may be related to a number of factors (e.g., initial lever-press training without shock; the delay between the lever press, the $10 \mathrm{~s} \mathrm{CS+,}$ and then shock; intermittent scheduling of the lever press-CS+shock associations, etc.). Over subsequent training sessions, a bias began to emerge away from the shock-producing lever, and shock intensities for each rat were incrementally adjusted on an individual basis so that, as a group, all rats eventually displayed a discrimination ratio of $85 \%$ of responses away from the CS+/ shock-producing lever. This required $\sim 25 \mathrm{~d}$ of training.

Rats were subsequently matched for performance in terms of discrimination ratio (Fig. $8 B$, left bars), total lever presses (Fig. $8 B$, inset), and shock intensity required to achieve criterion performance (AMPH group, $1.19 \pm 0.1 \mathrm{~mA}$; saline group, $1.21 \pm 0.1$ $\mathrm{mA})$. They then received repeated AMPH $(n=14)$ or saline $(n=$
13) treatment followed by a $7 \mathrm{~d}$ drug washout period. On the first day of punishment retraining, rats in both groups displayed a comparable number of total lever presses $\left(F_{(1,25)}=1.96\right.$, NS) (Fig. $8 B$, inset). However, although both groups of rats continued to display a response bias away from the shock-associated lever, this bias was significantly weaker in AMPHtreated rats $\left(F_{(1,25)}=4.68, p<0.05\right)$ (Fig. $8 B$, right bars). During subsequent retraining, AMPH-treated rats required more training sessions to achieve the criterion bias of $85 \%$ responding away from the CS+ lever $(1.7 \pm 0.2)$ relative to controls $\left(1.1 \pm 0.1 ; t_{(25)}=2.41, p<0.05\right)$. Thus, repeated AMPH treatment blunted memory recall of the bias away from the operanda associated with punishment.

With additional punishment training, rats in both groups displayed a comparable preference for the lever producing the neutral CS-0 compared with the CS+/footshock lever (Fig. 8C, left). However, this bias was not apparent on baseline days given before extinction tests of condition punishment, when no CS or shocks were presented (Fig. $8 C$, right).

The relative rates of responding on both levers during the tests of conditioned punishment during extinction (i.e., no footshocks) are presented in Figure $8 D$. Analysis of these data revealed a significant treatment group $\times$ lever interaction $\left(F_{(1,25)}=4.41, p<0.05\right)$. During these tests, control rats made proportionally fewer responses on the lever producing the aversive CS + versus the neutral CS-0 lever $(p<0.05)$, indicating that the CS+ alone had a demonstrable impact over the direction of instrumental responding. However, this bias was completely abolished in AMPH-treated rats, which responded equally on both levers. This impairment was not accompanied by any change in the overall rates of lever pressing $(p<0.60)$ (data not shown). It is interesting to note that previous studies have shown acute treatment with AMPH actually enhances the bias away from the CS+ associated lever using a similar task (Killcross et al., 1997a). This indicates that long-lasting neuroadaptations induced by repeated AMPH can affect this aspect of behavior in a manner opposite to that induced by acute treatment with this drug.

In contrast to the above-mentioned findings, rats in both groups displayed comparable levels of conditioned suppression in response to the CS+ relative to the CS- 0 (main effect of CS, $F_{(1,25)}=368.1, p<0.001$; treatment group $\times$ CS interaction, $F_{(1,25)}=0.15$, NS) (Fig. 8E). This indicates that repeated AMPH did not affect the expression of pavlovian conditioned emotional responses evoked by aversive stimuli. However, these treatments did induce a pronounce disruption in the ability to use these conditioned aversive stimuli to guide the direction of instrumental responding, in a manner similar to blockade of $\mathrm{D}_{1}$ or $\mathrm{D}_{2}$ receptors in the mPFC (Floresco and Magyar, 2006).

\section{Discussion}

Here we report that repeated exposure to AMPH leads to relatively long-lasting neurophysiological alterations in BLA $\rightarrow$ $\mathrm{mPFC}$ neurons. Foremost among these is a marked perturbation of dopaminergic modulation of BLA-evoked inhibitory and excitatory responses in these cells, mediated by $\mathrm{D}_{2}$ and $\mathrm{D}_{1}$ receptors, respectively. Parallel behavioral studies revealed that these treatments also disrupt decision making with conditioned punishment, reducing the impact that conditioned aversive stimuli exert 


\section{- BLA-evoked excitatory responses in MPFC neurons -}
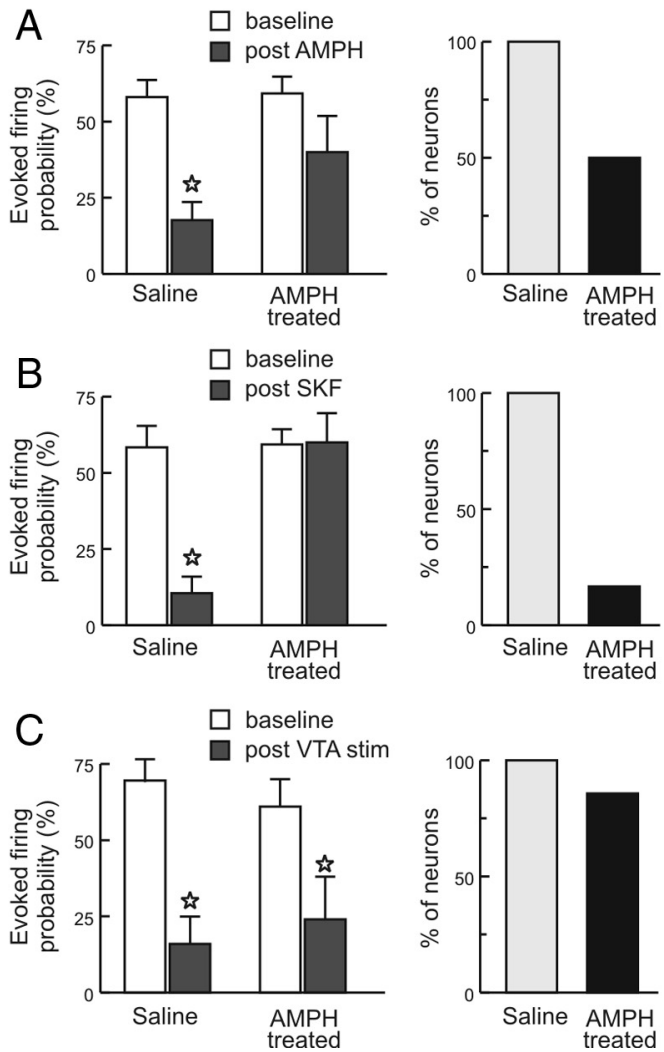

Figure 6. Changes in BLA-evoked firing induced by DA agonists and VTA stimulation. Left panels represent mean \pm SEM evoked firing probability under baseline conditions (white bars) and after treatment with DA agonists/VTA stimulation (gray bars); $\approx p<0.05$, difference relative to baseline. Right panels display the proportion of neurons recorded from saline- and AMPH-treated rats in which BLA-evoked firing was attenuated by these treatments. A, Treatment with AMPH ( $0.5 \mathrm{mg} / \mathrm{kg}$, i.v.) attenuates BLA-evoked firing in controls ( $n=9$ cells, 9 rats), but this effect was not statistically reliable in rats receiving repeated AMPH treatments $(n=8$ cells, 8 rats). $\boldsymbol{B}$, Treatment with the $D_{1}$ receptor agonist SKF81297 (0.5 mg/kg, i.v.) also attenuated BLA-evoked firing in control rats but not in AMPH-treated rats suggesting that these treatments induce a disruption in $D_{1}$ receptor function ( $n=6$ cells, 6 rats per group). C, Suppression of evoked-firing induced by VTA burst stimulation did not differ between salinetreated ( $n=6$ cells, 4 rats) and AMPH-treated ( $n=7$ cells, 7 rats) animals.

over the direction of instrumental responding, a process dependent on BLA-mPFC circuitry and mesocortical $\mathrm{D}_{1} / \mathrm{D}_{2}$ receptors. Of course, the AMPH treatment regimen used here is unlikely to rival the pattern or magnitude of AMPH intake typically associated with psychostimulant abuse. Nevertheless, these data suggest that even relatively moderate exposure to $\mathrm{AMPH}$ can induce long-lasting perturbations in BLA-PFC-DA interplay and corresponding changes in cognitive/emotional functions mediated by this circuitry.

\section{Neurophysiological alterations in BLA-PFC-DA circuitry induced by repeated AMPH}

We have shown previously that BLA-evoked monosynaptic excitatory responses and feedforward inhibition of mPFC neurons are attenuated by local application of DA or systemic treatment with $\mathrm{D}_{1}$ and $\mathrm{D}_{2} / \mathrm{D}_{4}$ agonists, respectively (Floresco and Tse, 2007), effects replicated here in saline-treated rats. Findings from in vitro studies suggest that these effects are likely mediated by presynaptic and postsynaptic actions of DA. $\mathrm{D}_{1}$ receptor activity suppresses pyramidal cell excitability and evoked EPSCs, reduc-
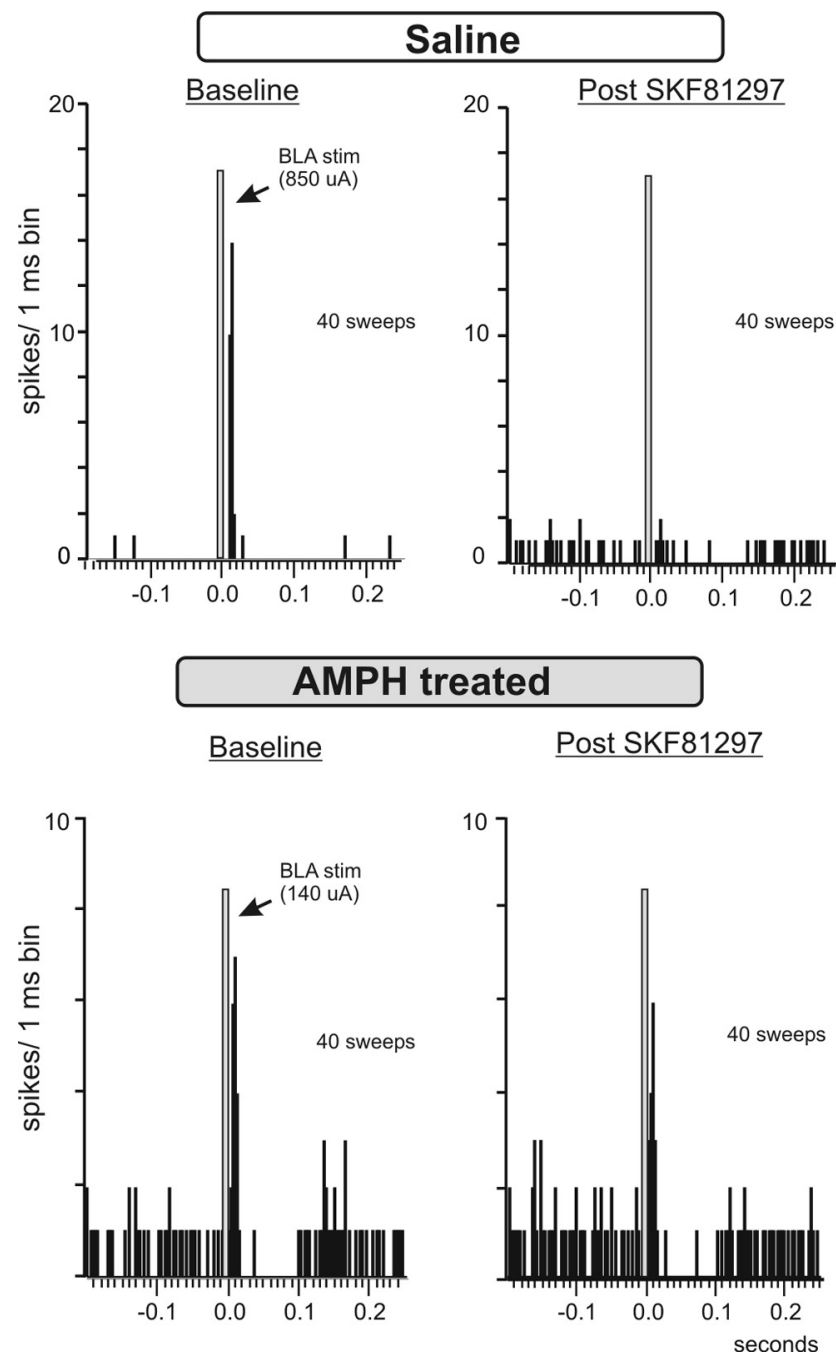

Figure 7. Representative PSTH illustrating the effect of $D_{1}$ receptor stimulation on BLA $\rightarrow$ $\mathrm{PFC}(+)$ in control and AMPH-treated rats. Each histogram is compiled from firing data obtained over 40 single-pulse stimulations of the BLA. Stimulation of $D_{1}$ receptors with SKF81297 reduced spike firing evoked by BLA stimulation in a neuron recorded from a saline-treated rat (top). However, similar treatments were ineffective at altering BLA-evoked firing in a rat that had received repeated AMPH (bottom).

ing postsynaptic $\mathrm{Na}^{+}$currents via PKA-dependent mechanisms (Peterson et al., 2006), and may also attenuate BLA inputs presynaptically (Gao et al., 2001; Seamans et al., 2001b; Paspalas and Goldman-Rakic, 2005). Conversely, activation of $\mathrm{D}_{2} / \mathrm{D}_{4}$ receptors can attenuate evoked IPSCs by reducing GABA release from local interneurons and desensitizing postsynaptic GABA receptors localized on mPFC pyramidal cells (Seamans et al., 2001a; Wang et al., 2002; Trantham-Davidson et al., 2004; Kroener and Lavin, 2010).

In contrast to what was observed in controls, repeated AMPH abolished the effects of $D_{1}$ and $D_{2}$ receptor activation on BLAevoked excitatory and inhibitory responses. These effects, obtained from adult animals, were observed at least 2 weeks after drug treatment, indicative of a persistent alteration in mesocortical DA signaling, which in turn may disrupt BLA-mPFC communication. The disruption of $\mathrm{D}_{1}$ receptor signaling observed here complements a growing literature showing that repeated psychostimulant exposure attenuates (or reverses) $\mathrm{D}_{1}$-mediated inhibition of mPFC pyramidal neurons recorded from brain slices of relatively young rats after short-term drug withdrawal, 

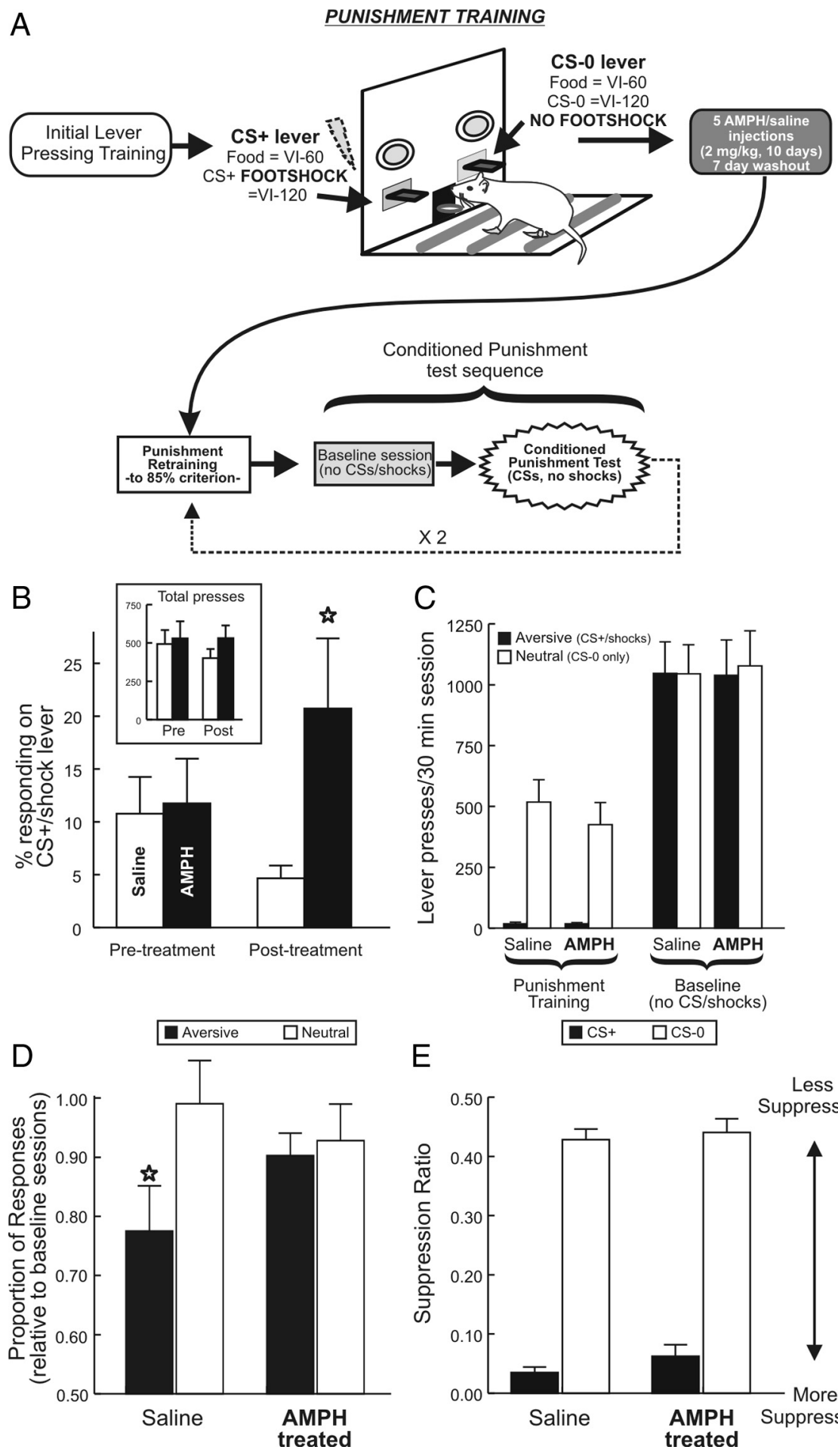

\section{E}

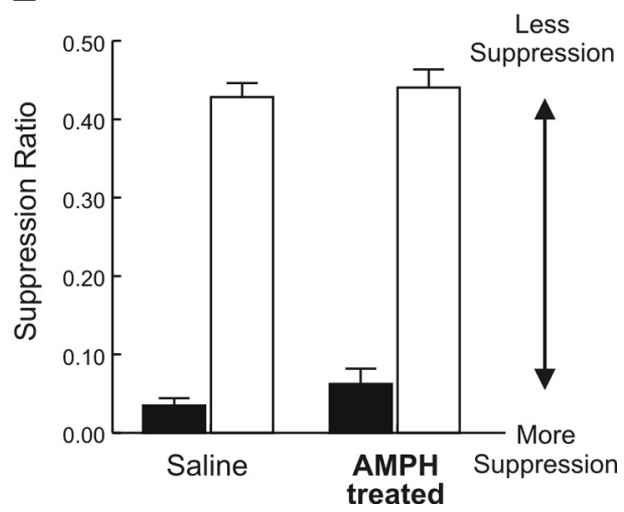

Figure 8. The effects of repeated AMPH treatment on decision making with conditioned punishment. $A$, Schematic of the training and testing schedule used for this experiment. After initial training to press two levers for food delivered on a VI 60 s schedule, rats were required to discriminate between one lever that delivered a compound conditioned stimuli (CS+) and footshock and another lever that delivered different compound stimulus (CS-0), each delivered on a VI 120 sschedule. After $\sim 25$ d of training, they received repeated AMPH or salinetreatments, a 7 ddrug washout period, retraining with punishment, and then two test of conditioned punishment. $\boldsymbol{B}$, After $\sim 25 \mathrm{~d}$ of initial punishment training, rats displayed a prominent bias away from the shock-associated lever (pretreatment). After repeated drug/saline treatment and drug washout, AMPH-treated rats displayed a significantly weaker bias than controls on the first day of punishment retraining ( $\approx p<0.05$, between-group difference). Inset displays total number of lever presses made by rats in both groups before repeated AMPH/saline treatment (Pre) and on the first day of retraining after treatment (Post), which did not differ between groups. C, After several sessions of punishment retraining, both groups showed a strong bias toward the neural, CS-0-associated lever (white bars) relative to the aversive, shock-associated lever (black bars). This bias was not apparent when the CSs/shockswere omitted during baselinelever-pressing sessions, when rats only received food. D, During the critical tests of conditioned punishment, saline-treated rats again biased instrumental responding away from the lever producing aversive $C S+$ (now, without shocks). However, AMPHtreated rats showed no bias. $\boldsymbol{E}$, Condition suppression of lever pressing (a measure of pavlovian fear) did not differ between the two groups. For $\boldsymbol{D}$ and $\boldsymbol{E}$, $₫ p<0.05$ aversive/CS + versusneutral/CS-0. potentially mediated through increases in PKA activity and alterations in corticotrophin-releasing factor functioning (Peterson et al., 2000, 2006; OrozcoCabal et al., 2008). Likewise, the reduced $\mathrm{D}_{2}$ modulation of BLA-evoked inhibition is in keeping with recent findings of Kroener and Lavin (2010) who reported that repeated cocaine abolished the ability of DA or the $\mathrm{D}_{2}$ agonist quinpirole to attenuate IPSCs evoked by nonspecific fiber stimulation. This latter effect may be attributable to elevated levels of AGS (a G-protein regulator that decreases $D_{2}$ signaling through $\mathrm{G}_{\mathrm{i} \alpha}$ ) (Bowers et al., 2004) and potentially through reduced expression of $\mathrm{D}_{2}$ receptors (Briand et al., 2008). Note that repeated AMPH did not completely abolish dopaminergic modulation of BLA-evoked inhibition, because the effect of $\mathrm{D}_{4}$ stimulation was left intact. Thus, repeated psychostimulant exposure induces a somewhat selective reduction in the efficacy of $\mathrm{mPFC}_{1}$ and $\mathrm{D}_{2}$ receptors, which in turn severely hampers the ability of DA to temper communication between the amygdala and frontal lobes. Whether these effects reflect a complete disruption of DA receptor functioning or a reduced sensitivity of these receptors remains a topic for future study.

It is notable that the disruption in dopaminergic modulation of BLA input to $\mathrm{mPFC}$ was also manifested as an apparent tolerance to the effects of acute AMPH on BLA-evoked responses. This stands in stark contrast to the wellestablished phenomenon that repeated psychostimulant exposure augments dopaminergic signaling in regions such as the nucleus accumbens, which is thought to underlie behavioral sensitization of their acute psychomotor effects (Kalivas and Stewart, 1991; Wolf et al., 1993; Seeman et al., 2002). Note that there have been other demonstrations that repeated psychostimulant treatment can induce tolerance to the disruptive effects of acute drug treatment on certain forms of PFCmediated cognition (Winstanley et al., 2007). Viewed collectively, these results suggest that behavioral abnormalities arising from repeated exposure to AMPH or cocaine may be the result of reduced DA signaling within the frontal lobes in addition to enhanced mesoaccumbens DA transmission.

Repeated AMPH also affected other properties of neurons within BLA $\rightarrow$ PFC circuitry. Although we did not observe an overall change in basal firing rates, we did observe an enhanced responsivity to the excitatory effects of BLA stimulation, con- 
sistent with previous in vitro and in vivo studies showing that these treatments increase mPFC cell excitability (Peterson et al., 2000, 2006; Parsegian et al., 2011). This may be related to increased pyramidal neurons spine densities that occur after repeated AMPH exposure (Robinson and Kolb, 1997). Conversely, recordings from AMPH-treated rats revealed that higher stimulation currents were required to induce a comparable duration of inhibition relative to controls. This latter effect may be attributable to a reduction in GABAergic interneurons, because treatment with a similar AMPH regimen is associated with a loss of parvalbumin immunoreactivity in the mPFC (Morshedi and Meredith, 2007).

We also observed that, in control rats, repetitive VTA stimulation increased mPFC neural firing, an effect linked to $D_{1}$ receptor activity (Lavin et al., 2005). However, this excitatory effect was abolished in AMPH-treated rats, similar to the effects of repeated cocaine (Nogueira et al., 2006), suggesting that these treatments disrupt the impact that midbrain DA neurons exert on mPFC excitability. Thus, in addition to disrupting the modulatory actions of DA on BLA $\rightarrow$ PFC transmission, repeated psychostimulant exposure may blunt communication between midbrain neurons and the frontal lobes, by both increasing cortical "noise" while simultaneously reducing "signal” from the VTA.

\section{Disruptions in decision making with conditioned punishment induced by repeated AMPH}

Our neurophysiological findings prompted us to examine the potential functional consequences of repeated AMPH treatment on cognitive processes known to be dependent on BLAPFC-DA circuitry. The conditioned punishment procedure models certain components of human decision-making tasks, requiring subjects to make discriminative responses to minimize presentation of secondary negative reinforcing stimuli. Notably, impairments in decision making are one of the more reliable cognitive deficits observed in stimulant abusers (Grant et al., 2000; Bechara et al., 2001; Rogers and Robbins, 2001). Normal conditioned punishment performance is dependent on the BLA (Killcross et al., 1997b) and is also disrupted by blockade of $\mathrm{D}_{1} / \mathrm{D}_{2}$ receptors in the $\mathrm{mPFC}$ (Floresco and Magyar, 2006).

After training and drug/saline treatment, AMPH-exposed rats showed a transient disruption in the retrieval of response-shock associations, as indicated by a reduced bias away from the shockassociated lever on the first day of retraining. During subsequent tests of conditioned punishment, rats pressed both levers for food as normal, but responding on one resulted in the presentation of the negative reinforcer (the shock-associated CS + ). Under these conditions, controls again responded less on the lever producing the aversive CS (now without footshock) relative to when no CSs/shocks were delivered. In stark contrast, AMPH-treated rats displayed no such bias, indicative of a disruption in the ability to use conditioned aversive stimuli to bias the direction of instrumental behavior. Note that, in both groups, the CS + did suppress lever pressing, demonstrating that mechanisms underlying expression of pavlovian fear responses were intact. Thus, AMPHtreated rats were still "fearful" of the CS + but were unable to use this emotional information to guide their instrumental behavior. This impairment is strikingly similar to that caused by intra-PFC infusions of $\mathrm{D}_{1}$ or $\mathrm{D}_{2}$ receptor antagonists (Floresco and Magyar, 2006). When viewed in light of our neurophysiological data, these behavioral findings suggest that (1) repeated AMPH exposure leads to a long-lasting disruption in the ability of condi- tioned aversive stimuli to guide the direction of volitional behavior and (2) these effects are likely attributable in part to perturbations in mesocortical DA signaling, which modulates information transfer from the BLA to the mPFC. Disruptions in mPFC $D_{1} / D_{2}$ function induced by repeated AMPH may have diminished the ability of the MPFC to monitor how ongoing instrumental behavior relates to the presentation of aversive stimuli (signaled by the BLA) and facilitate adjustments in response biases accordingly.

These findings provide important insight into the underlying neuroadapations that may occur in stimulant abusers, which may contribute to both their cognitive/emotional dysfunction and the persistence of the addiction itself. A key finding is that even moderate, repeated drug exposure disrupts $\mathrm{mPFC}$ DA receptor functioning, which may persist for weeks after the last drug exposure. As a consequence, the ability of DA to modulate communication between BLA and $\mathrm{mPFC}$ is perturbed, which, as our behavioral data imply, may reduce the impact that aversive stimuli or events have over the direction of behavior. This latter finding suggests that impairments in decision making observed in stimulant abusers may indeed be the result of repeated drug exposure, attributable in part to reduced impact that aversive stimuli have over the direction of behavior. Dysfunction in these processes may in turn contribute to the addiction process, by making abusers less sensitive to the negative consequences of continued drug use. As such, pharmacological treatments designed to normalize dopaminergic signaling within the frontal lobes may represent a promising target for treating some of the cognitive/emotional deficits associated with stimulant addiction, which in turn may facilitate attempts to discontinue drug use.

\section{References}

Au-Young SM, Shen H, Yang CR (1999) Medial prefrontal cortical output neurons to the ventral tegmental area (VTA) and their responses to burstpatterned stimulation of the VTA: neuroanatomical and in vivo electrophysiological analyses. Synapse 34:245-255.

Bechara A, Dolan S, Denburg N, Hindes A, Anderson SW, Nathan PE (2001) Decision-making deficits, linked to a dysfunctional ventromedial prefrontal cortex, revealed in alcohol and stimulant abusers. Neuropsychologia 39:376-389.

Bolles RC, Uhl CN, Wolfe M, Chase PB (1975) Stimulus learning versus response learning in a discriminated punishment situation. Learn Motiv 6:439-444

Bowers MS, McFarland K, Lake RW, Peterson YK, Lapish CC, Gregory ML, Lanier SM, Kalivas PW (2004) Activator of G protein signaling 3: a gatekeeper of cocaine sensitization and drug seeking. Neuron 42:269-281.

Briand LA, Flagel SB, Garcia-Fuster MJ, Watson SJ, Akil H, Sarter M, Robinson TE (2008) Persistent alterations in cognitive function and prefrontal dopamine D2 reecptor following extended, but not limited, access to self-administered cocaine. Neuropsychopharmacology 33:2969-2980.

Burette F, Jay TM, Laroche S (1997) Reversal of LTP in the hippocampal afferent fiber system to the prefrontal cortex in vivo with low-frequency patterns of stimulation that do not produce LTD. J Neurophysiol 78:1155-1160.

Condé F, Maire-Lepoivre E, Audinat E, Crépel F (1995) Afferent connections of the medial frontal cortex of the rat. II. Cortical and subcortical afferents. J Comp Neurol 352:567-593.

Coutureau E, Dix SL, Killcross AS (2000) Involvement of the medial prefrontal cortex-basolateral amygdala pathway in fear related behaviour in rats. Eur J Neurosci 12S:156.

de Almeida J, Mengod G (2010) D2 and D4 dopamine receptor mRNA distribution in pyramidal neurons and GABAergic subpopulations in monkey prefrontal cortex: implications for schizophrenia treatment. Neuroscience 170:1133-1139.

Dong Y, Nasif FJ, Tsui JJ, Ju WY, Cooper DC, Hu XT, Malenka RC, White FJ (2005) Cocaine-induced plasticity of intrinsic membrane properties in 
prefrontal cortex pyramidal neurons: adaptations in potassium currents. J Neurosci 25:936-940.

Ersche KD, Sahakian BJ (2007) The neuropsychology of amphetamine and opiate dependence: implications for treatment. Neuropsychol Rev 17: 317-336.

Ersche KD, Fletcher PC, Lewis SJ, Clark L, Stocks-Gee G, London M, Deakin JB, Robbins TW, Sahakian BJ (2005) Abnormal frontal activations related to decision-making in current and former amphetamine and opiate dependent individuals. Psychopharmacology 180:612-623.

Floresco SB, Grace AA (2003) Gating of hippocampal-evoked activity in prefrontal cortical neurons by inputs from the mediodorsal thalamus and ventral tegmental area. J Neurosci 23:3930-3943.

Floresco SB, Magyar O (2006) Mesocortical dopamine modulation of executive functions: beyond working memory. Psychopharmacology 188 : $567-585$.

Floresco SB, Tse MT (2007) Dopaminergic regulation of inhibitory and excitatory transmission in the basolateral amygdala-prefrontal cortical pathway. J Neurosci 27:2045-2057.

Floresco SB, Whelan JM (2009) Perturbations in different forms of cost/ benefit decision making induced by repeated amphetamine exposure. Psychopharmacology 205:189-201.

Floresco SB, St Onge JR, Ghods-Sharifi S, Winstanley CA (2008) Corticolimbic-striatal circuits subserving different forms of cost-benefit decision making. Cogn Affect Behav Neurosci 8:375-389.

Gabbott PL, Warner TA, Busby SJ (2006) Amygdala input monosynaptically innervates parvalbumin immunoreactive local circuit neurons in rat medial prefrontal cortex. Neuroscience 139:1039-1048.

Gao WJ, Krimer LS, Goldman-Rakic PS (2001) Presynaptic regulation of recurrent excitation by $\mathrm{D} 1$ receptors in prefrontal circuits. Proc Natl Acad Sci U S A 98:295-300.

Grant S, Contoreggi C, London ED (2000) Drug abusers show impaired performance in a laboratory test of decision making. Neuropsychologia 38:1180-1187.

Hotte M, Thuault S, Lachaise F, Dineley KT, Hemmings HC, Nairn AC, Jay TM (2006) $\mathrm{D}(1)$ receptor modulation of memory retrieval performance is associated with changes in pCREB and pDARPP-32 in rat prefrontal cortex. Behav Brain Res 171:127-133.

Ishikawa A, Nakamura S (2003) Convergence and interaction of hippocampal and amygdalar projections within the prefrontal cortex in the rat. J Neurosci 23:9987-9995.

Kadota T, Kadota K (2004) Neurotoxic morphological changes induced in the medial prefrontal cortex of rats behaviorally sensitized to methamphetamine. Arch Histol Cytol 67:241-251.

Kalivas PW, Stewart J (1991) Dopamine transmission in the initiation and expression of drug- and stress-induced sensitization of motor activity. Brain Res Rev 16:223-244.

Killcross AS, Everitt BJ, Robins TW (1997a) Symmetrical effects of amphetamine and alpha-flupenthixol on conditioned punishment and conditioned reinforcement: contrasts with midazolam. Psychopharmacology 129:141-152.

Killcross S, Robbins TW, Everitt BJ (1997b) Different types of fearconditioned behaviour mediated by separate nuclei within amygdala. Nature 388:377-380

Kita H, Kitai ST (1990) Amygdaloid projections to the frontal cortex and the striatum in the rat. J Comp Neurol 298:40-49.

Kroener S, Lavin A (2010) Altered dopamine modulation of inhibition in the prefrontal cortex of cocaine-sensitized rats. Neuropsychopharmacology 35:2292-2304.

Lavin A, Nogueira L, Lapish CC, Wightman RM, Phillips PE, Seamans JK (2005) Mesocortical dopamine neurons operate in distinct temporal domains using multimodal signaling. J Neurosci 25:5013-5023.

Lee JL, Dickinson A, Everitt BJ (2005) Conditioned suppression and freezing as measures of aversive Pavlovian conditioning: effects of discrete amygdala lesions and overtraining. Behav Brain Res 159:221-233.

London ED, Simon SL, Berman SM, Mandelkern MA, Lichtman AM, Bramen J, Shinn AK, Miotto K, Learn J, Dong Y, Matochik JA, Kurian V, Newton T, Woods R, Rawson R, Ling W (2004) Mood disturbances and regional cerebral metabolic abnormalities in recently abstinent methamphetamine abusers. Arch Gen Psychiatry 61:73-84.

Maroun M, Richter-Levin G (2003) Exposure to acute stress blocks the induction of long-term potentiation of the amygdala-prefrontal cortex pathway in vivo. J Neurosci 23:4406-4409.
Maslowski RJ, Napier TC (1991) Dopamine D1 and D2 receptor agonists induce opposite changes in the firing rate of ventral pallidal neurons. Eur J Pharmacol 200:103-112.

McDonald AJ (1991) Organization of amygdaloid projections to the prefrontal cortex and associated stratum in the rat. Neuroscience 44:1-14.

McDonald AJ, Mascagni F, Guo L (1996) Projections of the medial and lateral prefrontal cortices to the amygdala: a Phaseolus vulgaris leucoagglutinin study in the rat. Neuroscience 71:55-75.

Monterosso J, Ehrman R, Napier KL, O'Brien CP, Childress AR (2001) Three-decision making tasks in cocaine-dependent patients: do they measure the same construct? Addiction 96:1825-1837.

Morshedi MM, Meredith GE (2007) Differential laminar effects of amphetamine on prefrontal parvalbumin interneurons. Neuroscience 149: $617-624$.

Mulder AB, Arts MP, Lopes da Silva FH (1997) Short- and long-term plasticity of the hippocampus to nucleus accumbens and prefrontal cortex pathways in the rat, in vivo. Eur J Neurosci 9:1603-1611.

Mulkey RM, Malenka RC (1992) Mechanisms underlying induction of homosynaptic long-term depression in area CA1 of the hippocampus. Neuron 9:967-975.

Nayak S, Cassaday HJ (2003) The novel dopamine D4 receptor agonist (PD168,077 maleate): doses with different effects on locomotor activity are without effect in classical conditioning. Prog Neuropsychopharmacol Biol Psychiatry 27:441-449.

Nogueira L, Kalivas PW, Lavin A (2006) Long-term neuroadaptations produced by withdrawal from repeated cocaine treatment: role of dopaminergic receptors in modulating cortical excitability. J Neurosci 26:12308-12313.

Orozco-Cabal L, Liu J, Pollandt S, Schmidt K, Shinnick-Gallagher P, Gallagher JP (2008) Dopamine and corticotrophin-releasing factor synergistically alter basolateral amygdala-to-medial prefrontal cortex synaptic transmission: functional switch after chronic cocaine administration. J Neurosci 28:529-542.

Parsegian A, Glen WB Jr, Lavin A, See RE (2011) Methamphetamine selfadministration produces attentional set-shifting deficits and alters prefrontal cortical neurophysiology in rats. Biol Psychiatry 69:253-259.

Paspalas CD, Goldman-Rakic PS (2005) Presynaptic $D_{1}$ dopamine receptors in primate prefrontal cortex: target-specific expression in the glutamatergic synapse. J Neurosci 25:1260-1267.

Paxinos G, Watson C (1997) The rat brain in stereotaxic coordinates, Ed 3. San Diego: Academic.

Pérez-Jaranay JM, Vives F (1991) Electrophysiolgical study of the response of the medial prefrontal cortex neurons to stimulation of the basolateral nucleus of the amygdala in the rat. Brain Res 564:97-101.

Peterson JD, Wolf ME, White FJ (2000) Altered responsiveness of medial prefrontal cortex neurons to glutamate and dopamine after withdrawal from repeated amphetamine treatment. Synapse 36:342-344.

Peterson JD, Wolf ME, White FJ (2006) Repeated amphetamine administration decreases $\mathrm{D}_{1}$ dopamine receptor-mediated inhibition of voltagegated sodium currents in the prefrontal cortex. J Neurosci 26:3164-3168.

Pirot S, Godbout R, Mantz J, Tassin JP, Glowinski J, Thierry AM (1992) Inhibitory effects of ventral tegmental area stimulation on the activity of prefrontal cortical neurons: evidence for the involvement of both dopaminergic and GABAergic components. Neuroscience 49:857-865.

Pirot S, Jay TM, Glowinski J, Thierry AM (1994) Anatomical and electrophysiological evidence for an excitatory amino acid pathway from the thalamic mediodorsal nucleus to the prefrontal cortex in the rat. Eur J Neurosci 6:1225-1234.

Robinson TE, Kolb B (1997) Persistent structural modifications in nucleus accumbens and prefrontal cortex neurons produced by previous experience with amphetamine. J Neurosci 17:8491-8497.

Rogers RD, Robbins TW (2001) Investigating the neurocognitive deficits associated with chronic drug misuse. Curr Opin Neurobiol 11:250-257.

Seamans JK, Gorelova N, Durstewitz D, Yang CR (2001a) Bidirectional dopamine modulation of GABAergic inhibition in prefrontal cortical pyramidal neurons. J Neurosci 21:3628-3638.

Seamans JK, Durstewitz D, Christie BR, Stevens CF, Sejnowski TJ (2001b) Dopamine D1/D5 receptor modulation of excitatory synaptic inputs to layer V prefrontal cortex neurons. Proc Natl Acad Sci U S A 98:301-306.

Seeman P, Tallerico T, Ko F, Tenn C, Kapur S (2002) Amphetaminesensitized animals show a marked increase in dopamine D2 high recep- 
tors occupied by endogenous dopamine, even in the absence of acute challenges. Synapse 46:235-239.

Sesack SR, Deutch AY, Roth RH, Bunney BS (1989) Topographical organization of the efferent projections of the medial prefrontal cortex in the rat: an anterograde tract-tracing study with Phaseolus vulgaris leucoagglutinin. J Comp Neurol 290:213-242.

Simon NW, Mendez IA, Setlow B (2007) Cocaine exposure causes longterm increases in impulsive choice. Behav Neurosci 121:543-549.

Tierney PL, Dégenètais E, Thierry AM, Glowinski J, Gioanni Y (2004) Influence of the hippocampus on interneurons of the rat prefrontal cortex. Eur J Neurosci 20:514-524.

Trantham-Davidson H, Neely LC, Lavin A, Seamans JK (2004) Mechanisms underlying differential $D_{1}$ versus $D_{2}$ dopamine receptor regulation of inhibition in prefrontal cortex. J Neurosci 24:10652-10659.
Wang X, Zhong P, Yan Z (2002) Dopamine $\mathrm{D}_{4}$ receptors modulate GABAergic signaling in pyramidal neuons of prefrontal cortex. J Neurosci 22:9185-9193.

Winstanley CA, LaPlant Q, Theobald DE, Green TA, Bachtell RK, Perrotti LI, DiLeone RJ, Russo SJ, Garth WJ, Self DW, Nestler EJ (2007) DeltaFosB induction in orbitofrontal cortex mediates tolerance to cocaine-induced cognitive dysfunction. J Neurosci 27:10497-10507.

Wolf ME, White FJ, Nassar R, Brooderson RJ, Khansa MR (1993) Differential development of autoreceptor subsensitivity and enhanced dopamine release during amphetamine sensitization. J Pharmacol Exp Ther 264: 249-255.

Zhang K, Tarazi FI, Baldessarini RJ (2000) Dopamine D(4) receptors in rat forebrain: unchanged with amphetamine-induced behavioral sensitization. Neuroscience 97:211-213. 